\title{
The GLACE-Hydrology Experiment: Effects of Land-Atmosphere Coupling on Soil Moisture Variability and Predictability ${ }^{0}$
}

\author{
Sanjiv Kumar, ${ }^{a}$ Matthew Newman, ${ }^{\text {b,c }}$ David M. Lawrence, ${ }^{\mathrm{d}}$ Min-Hui Lo, ${ }^{\mathrm{e}}$ Sathish Akula, ${ }^{\mathrm{f}}$ \\ CHIA-WEI LAN, ${ }^{\text {e }}$ BEN LIVNEH, ${ }^{\text {b,g }}$ AND DANICA LOMBARDOZZI ${ }^{\mathrm{d}}$ \\ ${ }^{a}$ Earth System Science Program, School of Forestry and Wildlife Sciences, Auburn University, Auburn, Alabama \\ ${ }^{\mathrm{b}}$ Cooperative Institute for Research in Environmental Sciences, University of Colorado Boulder, Boulder, Colorado \\ ${ }^{\mathrm{c}}$ NOAA Physical Sciences Laboratory Boulder, Colorado \\ ${ }^{\mathrm{d}}$ National Center for Atmospheric Research, Boulder, Colorado \\ e Department of Atmospheric Sciences, National Taiwan University, Taiwan \\ ${ }^{\mathrm{f}}$ Department of Computer Science and Software Engineering, Auburn University, Auburn, Alabama \\ ${ }^{\mathrm{g}}$ Department of Civil, Environmental, and Architectural Engineering, University of Colorado Boulder, Boulder, Colorado
}

(Manuscript received 7 August 2019, in final form 1 April 2020)

\begin{abstract}
The impact of land-atmosphere anomaly coupling on land variability is investigated using a new two-stage climate model experimental design called the "GLACE-Hydrology" experiment. First, as in the GLACECMIP5 experiment, twin sets of coupled land-atmosphere climate model (CAM5-CLM4.5) ensembles are performed, with each simulation using the same prescribed observed sea surface temperatures and radiative forcing for the years 1971-2014. In one set, land-atmosphere anomaly coupling is removed by prescribing soil moisture to follow the control model's seasonally evolving soil moisture climatology ("land-atmosphere uncoupled"), enabling a contrast with the original control set ("land-atmosphere coupled"). Then, the atmospheric outputs from both sets of simulations are used to force land-only ensemble simulations, allowing investigation of the resulting soil moisture variability and memory under both the coupled and uncoupled scenarios. This study finds that in midlatitudes during boreal summer, land-atmosphere anomaly coupling significantly strengthens the relationship between soil moisture and evapotranspiration anomalies, both in amplitude and phase. This allows for decreased moisture exchange between the land surface and atmosphere, increasing soil moisture memory and often its variability as well. Additionally, land-atmosphere anomaly coupling impacts runoff variability, especially in wet and transition regions, and precipitation variability, although the latter has surprisingly localized impacts on soil moisture variability. As a result of these changes, there is an increase in the signal-to-noise ratio, and thereby the potential seasonal predictability, of SST-forced hydroclimate anomalies in many areas of the globe, especially in the midlatitudes. This predictability increase is greater for soil moisture than precipitation and has important implications for the prediction of drought.
\end{abstract}

\section{Introduction}

Understanding the causes and predictability of drought is of societal importance (Cheng et al. 2016; Evans et al. 2017; Held et al. 2005; Hoerling et al. 2014; Livneh and Hoerling 2016). The 2012 drought, the most spatially extensive U.S. drought in the instrumental record from 1895 to the present, resulted in $\$ 33.9$ billion economic losses, largely from the agricultural sector (Hoerling et al.

Supplemental information related to this paper is available at the Journals Online website: https://doi.org/10.1175/JCLI-D-190598.s1.

Corresponding author: Sanjiv Kumar, szk0139@auburn.edu
2014; NCEI 2019; Rippey 2015). Many investigators have highlighted the importance of remote oceanic forcing on drought development and prediction (Ault et al. 2018; Hoell et al. 2016; Kam et al. 2014; Swain 2015; Wang et al. 2014; Wei et al. 2016). However, in their drought synthesis study, Schubert et al. (2016) demonstrated limitations in large-scale SST-driven predictability of droughts and suggested that additional sources of predictability should be explored, including land-atmosphere coupling.

A significant precipitation deficit relative to normal is said to cause a "meteorological drought"; an "agricultural drought" may be a consequence of the resulting soil moisture deficit (Sheffield and Wood 2011), which also incorporates effects of the land processes, such as soil moisture memory, snowmelt, runoff, and evapotranspiration. 
Soil moisture exhibits considerably longer memory than precipitation, so soil moisture memory can potentially contribute to drought predictability (Amenu et al. 2005; Guo et al. 2012; Kumar et al. 2014b; Orth and Seneviratne 2013; PaiMazumder and Done 2016), including through a climate process called "soil moisture anomaly reemergence" described by Kumar et al. (2019). Their study showed that root zone soil moisture anomalies could recur several seasons or more than a year after they were initiated, indicating potential interannual predictability.

Drought impacts vegetation, whose phenology in turn affects surface reflective properties (surface albedo) and energy and momentum fluxes in the boundary layer (Bonan 2016; Evans et al. 2017; Koster and Walker 2015; Meng et al. 2014). In a regional climate model study, Evans et al. (2017) found that vegetation processes intensified droughts by about $10 \%$ in southeast Australia. Meng et al. (2014) found that an interactive vegetation scheme can have both positive and negative feedbacks on drought development in Australia. The positive feedback due to decreased soil moisture and increased surface albedo dominated on a shorter time scale (1 month), whereas the lagged vegetation response (decreased vegetation) caused negative feedback on a longer time scale.

In addition to local soil moisture and vegetation feedbacks, land-atmosphere coupling can also affect global circulation patterns, for example by warming the near-surface air temperature (Berg et al. 2014; Delworth and Manabe 1988), and the resulting circulation changes may feed back on precipitation anomalies, such as in the Great Plains (Schubert et al. 2008). In the continental United States, a dry surface soil moisture anomaly can generate circulation anomalies by creating a high over the west-central United States, with a low to its east, further strengthening central U.S. warming and drying (Koster et al. 2016). Teng et al. (2019) found a robust circumglobal response due to heating anomalies induced by arbitrarily prescribing soil moisture to have a zero value at selected domains in the continental United States.

The hypothesis motivating our study is that land processes and their coupled interactions with the atmosphere can enhance soil moisture predictability beyond what is attributable to anomalous SST forcing alone. We posit three principal mechanisms: 1) the climate forcing remote pathway, where soil moisture anomalies drive changes in the remote circulation patterns and thereby modify advection of atmospheric moisture into or out of the region (Koster et al. 2016; Schubert et al. 2008); 2) the climate forcing local pathway, where soil moisture anomalies influence boundary layer growth, clouds, and precipitation triggering (Findell and Eltahir 2003; Santanello et al. 2018; Tawfik and Dirmeyer 2014); and 3) the land processes pathway, where local processes control soil moisture variability including evapotranspiration, runoff, soil moisture memory, and reemergence. Collectively, these three mechanisms may be considered to be land-atmosphere coupling effects. Importantly, land-atmosphere coupling is stronger during summer when the predictability due to large-scale remote oceanic forcing appears to be limited (Dirmeyer 2011; Koster et al. 2004; Seager and Hoerling 2014; Seager et al. 2015).

The Global Land-Atmosphere Coupling Experiment (GLACE) phase 1 aimed to isolate the impact of interactive soil moisture on precipitation variability in a multimodel framework (Koster et al. 2004, 2006). The GLACE-CMIP5 experiments extended the GLACE experiments to climate models from phase 5 of the Coupled Model Intercomparison Project. They found a stronger influence of land-atmosphere coupling on extreme daytime temperatures than on mean temperatures, while its effect on precipitation was less robust (Seneviratne et al. 2013; Taylor et al. 2012). Orth and Seneviratne (2017) found that land-atmosphere coupling increased surface temperature variability by $10 \%-$ $50 \%$ in the warm season, comparable in magnitude to the effect of teleconnections from SST anomalies.

A knowledge gap exists in understanding the effects of land-atmosphere coupling on soil moisture memory and variability and their impact on "agricultural drought." Our new two-stage experimental design, which we call the GLACE-Hydrology Experiment, addresses this knowledge gap (Fig. 1). First, as in the GLACE-CMIP5 experiment, twin sets of coupled land-atmosphere climate model (CAM5-CLM4.5) ensembles are performed, with each simulation using the same prescribed observed sea surface temperatures and radiative forcing for the years 19712014. In one set of ensembles, land-atmosphere anomaly coupling is removed through the prescription of the control model's seasonally evolving soil moisture climatology ("land-atmosphere uncoupled"), enabling a contrast with the other ("land-atmosphere coupled") set of ensembles. Then, the atmospheric output from both sets of simulations is used to force land-only ensemble simulations, allowing investigation of the resulting soil moisture variability under both the "coupled" and "uncoupled" scenarios. Note that, as in all GLACE experiments, the control model's soil moisture climatology includes the mean effects of land-atmosphere coupling, whose impact on the atmosphere carries over into the uncoupled experiments. Therefore, when we use the term "uncoupled" it is meant as shorthand for "anomaly uncoupled" from this point forward.

There are considerable uncertainties in the representation of the land processes, vegetation parameterizations, and soil moisture-atmosphere coupling in climate 
LA coupled (ATM)

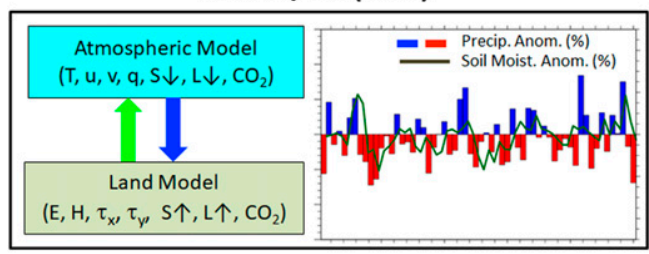

LA uncoupled (ATM)

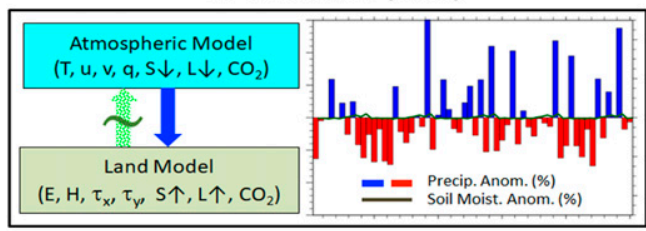

Stage 1: Generate atmospheric forcing data under LA coupled and uncoupled scenarios using AMIP style run
LA coupled (LAND)

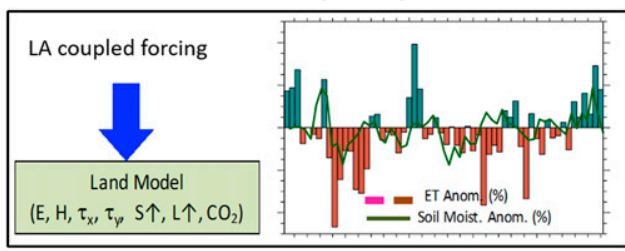

LA uncoupled (LAND)

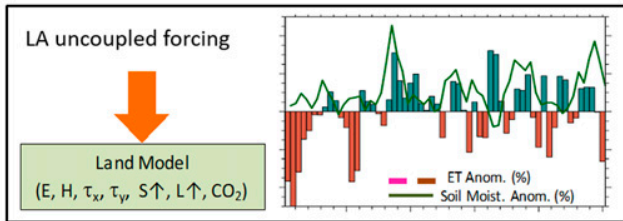

Stage 2: Run offline land/hydrology model simulations using atmospheric forcing from Stage 1

FIG. 1. Schematic of the GLACE-Hydrology experiment: (left) the generation of atmospheric forcing with landatmosphere (LA) coupled and LA uncoupled experiments using the AMIP-style run (see text) and (right) the LA coupled LAND and LA uncoupled LAND experiments with the respective climate forcing from stage 1.

models (Dahlin et al. 2015; de Noblet-Ducoudré et al. 2012; Dirmeyer et al. 2006, 2013; Ferguson et al. 2012; Guo and Dirmeyer 2006; Kumar et al. 2013; Liu et al. 2017; Pitman et al. 2009). In general, CAM5-CLM4 exhibits relatively weak land-atmosphere coupling when compared to the observational and reanalysis-based coupling strength estimates (Mei and Wang 2012). Still, many studies have employed the NCAR climate model to conduct climate predictability studies (Dirmeyer et al. 2013; Infanti and Kirtman 2016; Kumar et al. 2014b; Yeager et al. 2018).

We organize this paper as follows: section 2 describes the experimental design, data, and methods. Next, to place the drivers of the soil moisture variability in our experimental setup in context, we describe a simple budget of soil moisture variability in section 3 . Section 4 presents results, divided into three main subcategories: (i) characteristics of the GLACE-Hydrology experiment that help us to understand results in succeeding subsections, (ii) changes in the soil moisture variability and its drivers, and (iii) the impact of coupling on the potential predictability of seasonal precipitation and soil moisture anomalies. Finally, we present a discussion in section 5 that also covers key conclusions from this study.

\section{Data and methods}

\section{a. The GLACE-Hydrology experiment design}

Our experimental design follows the Global LandAtmosphere Coupling Experiment methodology (GLACE and GLACE-CMIP5) (Koster et al. 2004; Seneviratne et al. 2013) with the addition of subsequent land-only experiments aimed at isolating the soil hydrology responses to land-atmosphere coupling (Fig. 1 and Table 1). Based on atmospheric general circulation model (GCM) simulations whose ocean boundary conditions are specified from observations, i.e., a standard AMIP (Atmospheric Model Intercomparison Project) style run, we conduct two sets of model runs: 1) an ensemble of control runs in which the land and atmosphere are interactively coupled (LA-coupled ATM), and 2) an ensemble of experimental runs in which the landatmosphere anomaly coupling is removed by specifying the seasonally evolving soil moisture climatology extracted from the respective control experiment; that is, removing the direct effects of anomalous soil moisture interactions with the atmosphere (which we will call "LA-uncoupled ATM"). (As noted in the introduction, indirect effects may remain since the control model's soil moisture climatology includes rectified anomaly interactions.) We then use the 3-hourly atmospheric forcing data archived from both sets of ensembles to run land-only simulations, LA-coupled LAND and LAuncoupled LAND, allowing for consistent comparison of the soil moisture variability associated with and without the land-atmosphere coupling.

We implemented the GLACE-Hydrology experiment in the Community Earth System Modeling (CESM) framework (Hurrell et al. 2013) using the Community Atmospheric Model version 5 and Community Land Model version 4.5 (CAM5 + CLM4.5) and performed 
TABLE 1. The GLACE-Hydrology Experiment details and its comparison with other experiments. GSWP3 is the Global Soil Wetness Project Phase 3.

\begin{tabular}{|c|c|c|c|c|c|c|}
\hline Expt type & Experiment ID & $\begin{array}{l}\text { Soil } \\
\text { moisture }\end{array}$ & Climate forcing & SST forcing & Variables analyzed & Reference \\
\hline AMIP type & LA coupled ATM & Interactive & $\begin{array}{l}\text { Interactive } \\
\text { atmosphere model } \\
\text { (CAM5) (Neale } \\
\text { et al. 2010) }\end{array}$ & $\begin{array}{l}\text { Time-evolving observed } \\
\text { SST from } 1971 \text { to } 2014 \\
\text { (Hurrell et al. 2008) }\end{array}$ & $\begin{array}{l}\text { Precipitation and } \\
\text { temperature }\end{array}$ & \multirow{2}{*}{$\begin{array}{l}\text { The GLACE- } \\
\text { Hydrology } \\
\text { Expt }\end{array}$} \\
\hline Land-only & $\begin{array}{l}\text { LA coupled LAND } \\
\text { LA uncoupled LAND }\end{array}$ & $\begin{array}{l}\text { Interactive } \\
\text { Interactive }\end{array}$ & $\begin{array}{l}\text { LA coupled ATM } \\
\text { LA uncoupled ATM }\end{array}$ & - & $\begin{array}{l}\text { Soil moisture and } \\
\text { evapotranspiration }\end{array}$ & \\
\hline Land-only & CLM4.5 (observation) & Interactive & GSWP3 & - & $\begin{array}{l}\text { Soil moisture, } \\
\text { precipitation, } \\
\text { and ET }\end{array}$ & $\begin{array}{l}\text { Lawrence } \\
\text { et al. } \\
\text { (2019) }\end{array}$ \\
\hline
\end{tabular}

$2 \times 10$-member ensemble experiments with the observed monthly sea surface temperature data from 1971 to 2014 (Hurrell et al. 2008) as the oceanic boundary condition. Each ensemble member was created by a small random perturbation to initial atmospheric conditions using the same method as in the CESM Large Ensemble (Kay et al. 2015). The same land model initial conditions, taken from a transient land-only CLM4.5 simulation are used in all the simulations. For each ensemble member, we first perform the control experiment and then use its soil moisture climatology to make the corresponding LA-uncoupled ATM simulation. The 3-hourly atmospheric data from each ensemble member, having been saved, are then (in stage 2) used to drive the corresponding land-only simulation.

Table 1 lists the experiments, the corresponding experiment ID, and the variables analyzed. In general, stage 1 (ATM) provides the surface atmospheric variables, temperature and precipitation, and stage 2 (LAND) provides the response variables, evapotranspiration and soil moisture, which are the main focus of this study. Table 1 also compares the key features of the GLACEHydrology experiments with the standard CLM landonly experiment using observed atmospheric forcing (Lawrence et al. 2019).

\section{b. Community Land Model}

The CLM4.5 has a 10-layer fixed-depth soil moisture scheme extending downward to 3.8-m depth. CLM solves the one-dimensional Richard's equation within each soil column, which can share several plant functional types to account for vegetation heterogeneity at the surface. Plant functional types describe vegetation structure in terms of leaf properties, canopy heights, and root distributions (Bonan et al. 2002; Oleson et al. 2013). CLM also has a prognostic seasonal cycle of vegetation evolution, emergence, and senescence of leaves and vegetation heights based on the Biomebiogeochemical cycle model (Thornton and Rosenbloom 2005; Thornton et al. 2002).

To prescribe the soil moisture climatology, we implemented the GLACE-CMIP5 design (Seneviratne et al. 2013), modified by reducing temperature variability differences in the high latitudes in the LAuncoupled ATM experiments (Fig. 2a). The modified scheme adjusts liquid and ice fractions of total soil water to be consistent with the meteorological conditions at the current time step in the model. This takes liquid and ice fraction in the current time step and distributes the seasonal climatology of total soil water accordingly. We found that the GLACE-CMIP5 scheme, where liquid and ice fractions were set to seasonal climatological values, was creating an extra heat sink, specifying a larger fraction of ice content than desired. This extra heat melted the ice, resulting in a larger temperature mean and variability difference between the LA-coupled and LA-uncoupled ATM experiments in the high latitudes. The modified scheme removed the temperature mean and variability difference between two experiments in the high latitudes (Fig. 2a; see also Fig. S1 in the online supplemental material).

\section{c. Statistical methods}

We have used a Monte Carlo method to compute the statistical significance of the differences in variance and correlation between the LA-coupled and LA-uncoupled experiments. For example, we applied the following steps for the significance calculation of the soil moisture and ET correlations difference: 1 ) compute the correlation for each month and each ensemble member separately using monthly anomalies data from 1979 to 2014; 2) make a mixed pool of 20 ensemble members 
(a) JJA Temperature Variability $\left({ }^{\circ} \mathrm{C}\right)$

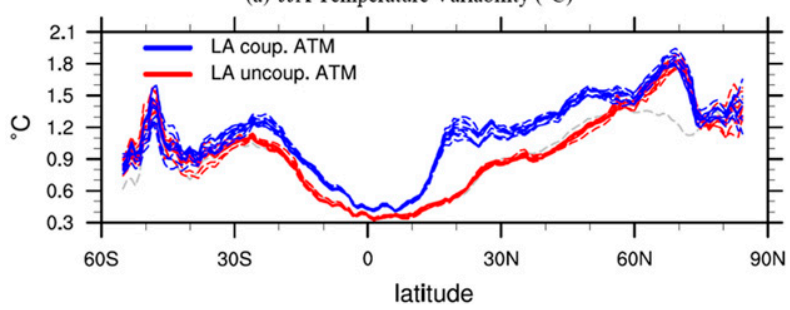

(b) JJA ET Variability ( $\mathrm{mm} / \mathrm{month})$

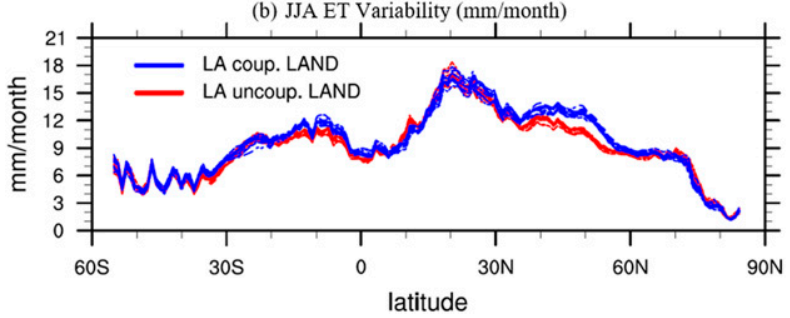

FIG. 2. Effects of the land-atmosphere coupling on hydroclimate variability. The figure shows the JJA (a) zonal average variance of the temperature $\left({ }^{\circ} \mathrm{C}\right)$ and (b) evapotranspiration $\left(\mathrm{mm} \mathrm{month}{ }^{-1}\right)$ in the LA-coupled (blue lines) and LA-uncoupled (red lines) experiments. All $10 \times 2$ ensembles are shown here. Interannual variance is calculated at each grid cell, then zonal land average is computed, and its squared root quantities are shown. The gray line in (a) shows the GLACE-CMIP5 implementation of the LA-uncoupled ATM experiment. The new scheme in the GLACE-Hydrology experiment significantly reduces the difference between coupled and uncoupled experiments at high latitudes.

(10 from the LA-coupled LAND and 10 from the LAuncoupled LAND); 3) randomly select, with replacement, two groups of 10 ensemble member from the mixed pool, and compute their differences; and 4) repeat the process 1000 times and sort the range of the differences. A $95 \%$ statistically significant result then occurs if the average ensemble difference between the LA-coupled LAND and LA-uncoupled LAND experiments falls outside the $95 \%$ range of the random sample in the given month.

\section{d. Predictability metric}

To diagnose potential predictability, we determined the squared signal-to-noise ratio (SNR) from each set of experiments. Following Guo et al. (Guo et al. 2011), SNR is defined as

$$
\mathrm{SNR}=\frac{V_{s}}{V_{n}}=\frac{\frac{1}{N} \sum_{n}\left(y_{\cdot n}-y_{. .}\right)^{2}}{\frac{1}{N E} \sum_{n} \sum_{e}\left(y_{e, n}-y_{\cdot n}\right)^{2}},
$$

where $y_{. .}=(1 / N E) \sum_{e=1}^{E} \sum_{n=1}^{N} y_{e, n}$ and $y_{\cdot n}=(1 / E) \sum_{e=1}^{E} y_{e, n}$. The term $V_{s}$ represents the variability of the ensemble mean, which may be thought of as the potentially predictable (SST-forced) signal; $V_{n}$ is variability about the ensemble mean, or the noise term. The null hypothesis of no predictability can be rejected at the $95 \%$ level if SNR $\geq F_{N-1, N(E-1)}^{0.05} \times[(N-1) / N(E-1)]$, where $F_{N-1, N(E-1)}^{0.05}$ is the upper $5 \%$ threshold for the $F$ distribution with $N$ and $N(E-1)$ degrees of freedom. The "signal-to-total ratio" (STR) is then defined as STR = $\mathrm{SNR} /(\mathrm{SNR}+1)$, which varies between 0 and 1 . Note that for an infinite-member perfect-model ensemble, we may measure forecast skill of the predicted signal by the mean anomaly correlation, which can be shown is equivalent to the square of STR (Sardeshmukh et al. 2000); that is, STR is a measure of potential predictability.

To test the null hypothesis that the predictability signal is statistically indistinguishable between the LA coupled and LA uncoupled ensembles, we use a signal-to-signal ratio (SSR) between the two sets of experiments:

$$
\mathrm{SSR}=\log _{10} \frac{V_{S}^{\text {LA_coup. }}}{V_{S}^{\text {LA_uncoup. }} .}
$$

Under the null assumption that the two experiments have the same total variability, the SSR can be computed using STR in the respective experiments. The null hypothesis can be rejected if $\left(V_{S}^{\mathrm{LA} \_ \text {coup. }} / V_{S}^{\mathrm{LA}}{ }_{\text {uncoup. }}\right) \geq F_{N-1, N-1}^{0.05}$, in which case, land-atmosphere coupling may be said to have significantly enhanced potential predictability (Guo et al. 2011).

\section{A simple framework to diagnose coupling impacts on soil moisture variability}

To better comprehend the complexities of landatmosphere anomaly coupling and its impact on soil moisture variability, let us consider the following simple model for the monthly variation of soil moisture anomalies:

$$
S_{t}^{\prime}-S_{t-1}^{\prime}=P_{t}^{\prime}-\mathrm{ET}_{t}^{\prime}-R_{t}^{\prime},
$$

where the left-hand side represents the change in soil moisture anomalies $S^{\prime}$ over the time interval $[t-1, t]$, and $P_{t}^{\prime}, \mathrm{ET}_{t}^{\prime}$, and $R_{t}^{\prime}$ are the accumulated anomalous precipitation, evapotranspiration, and runoff, respectively, during that time interval. Anomalies are determined relative to the long-term monthly climatology. Multiplying both sides of (3) by $S_{t}^{\prime}$, taking a time average, and rearranging terms yields a budget for soil moisture variance:

$$
\overline{S_{t}^{\prime} S_{t}^{\prime}}=\overline{S_{t}^{\prime} S_{t-1}^{\prime}}+\overline{P_{t}^{\prime} S_{t}^{\prime}}-\overline{\mathrm{ET}_{t}^{\prime} S_{t}^{\prime}}-\overline{R_{t}^{\prime} S_{t}^{\prime}} .
$$

Expressing all the covariance terms $\overline{X^{\prime} Y^{\prime}}$ in terms of correlation coefficients $\left(\rho_{X Y}\right)$ and corresponding standard deviations 
$\left(\sigma_{X}\right.$ and $\left.\sigma_{Y}\right)$, such that $\overline{X^{\prime} Y^{\prime}}=\rho_{X Y} \sigma_{X} \sigma_{Y}$, and then dividing through by $\sigma_{S_{t}}$, (4) becomes

$$
\sigma_{S_{t}}=\rho_{S_{t} S_{t-1}} \sigma_{S_{t-1}}+\rho_{P_{t} S_{t}} \sigma_{\mathrm{Pt}}-\rho_{\mathrm{ET}_{t} S_{t}} \sigma_{\mathrm{ET}_{t}}-\rho_{R_{t} S_{t}} \sigma_{R_{t}} .
$$

The first term on the right-hand side represents the effect of soil moisture memory, modulated by the seasonal cycle of soil moisture variability (i.e., when $\sigma_{S_{t}} \neq \sigma_{S_{t-1}}$ ). The second term is soil moisture-precipitation covariability, which for positive correlation balances increased soil moisture variability (since standard deviations are all positive quantities). The final terms represent soil moisture-evapotranspiration covariability and soil moisture-runoff covariability, which for positive correlations each balance decreased soil moisture variability. It is important to note that as a variance budget, Eq. (5) is best used in a diagnostic sense, to quantify the relative influence of each of the four terms on soil moisture variability. While strong correlations between soil moisture and other process anomalies in (5) may represent direct effects of coupling, they may instead reflect a third process that drives both; conversely, low correlations do not necessarily rule out the possibility of coupling, since coupled variables need not be exactly in phase. However, we can use Eq. (5) to determine land-atmosphere coupling impacts by examining the extent to which its terms significantly change between the LA-coupled and LA-uncoupled experiments.

We use (5) rather than (4) as the soil variability budget because its terms can be easily related to other landatmosphere coupling studies. For example, previous GLACE studies have investigated the soil moistureevapotranspiration covariability term and its impacts on precipitation and temperature variability (Guo et al. 2006; Koster et al. 2010, 2004, 2006). Keeping all other factors the same, increased soil moisture-evapotranspiration covariability decreases soil moisture variability (e.g., Teuling and Troch 2005). Similarly, soil moisture memory $\rho_{S_{t} S_{t-1}}$ has been extensively studied (Amenu et al. 2005; Dirmeyer et al. 2016; Entin et al. 2000; Koster and Suarez 2001; NicolaiShaw et al. 2016; Orth and Seneviratne 2012; Vinnikov et al. 1996; Wu and Dickinson 2004; Wu et al. 2002). These studies have found that the root zone soil moisture memory time scale ranges from 2 to 4 months. We are interested in investigating the coevolution of all four terms in an internally consistent climate modeling experiment and identifying their relative importance for soil moisture predictability.

We use a 1-month lag correlation for total soil moisture (3.8-m depth in CLM4.5) and its interannual standard deviation in our calculations. Total soil moisture depth is necessary to be consistent with the remaining terms in Eq. (5) that represent total precipitation, evapotranspiration, and runoff variabilities. Accordingly, the memory and variability differences are computed using total soil moisture. Using only the root zone soil moisture does not change any interpretation of our result, but the variance budgets do not close because the root zone does not account for all water available in the soil column.

\section{Results}

We first describe those experimental characteristics that both aid our understanding of how land-atmosphere coupling changes soil moisture variability and provide context for this study vis-à-vis the existing GLACE literature. Next, we show how land-atmosphere coupling altered soil moisture variability and the terms in the soil moisture variability budget discussed above, notably the soil moisture memory. Finally, we estimate how coupling acts to enhance the potential predictability of SST-forced changes in precipitation and soil moisture.

\section{a. Characterization of the GLACE-Hydrology experiment}

\section{1) HYDROCLIMATE VARIABILITY}

Land-atmosphere coupling increased temperature and ET variability in low- to midlatitude regions and during the summer. Figure 2 shows the zonal mean, taken only over land, of near-surface air temperature and ET variability for both the coupled and uncoupled ensembles during the boreal summer season (JJA). (For this and subsequent figures, "variability" is measured by standard deviation, determined by the square root of the 10member ensemble mean variance.) Land-atmosphere coupling significantly increased surface air temperature variability in the low and middle latitudes, consistent with previous studies (Berg et al. 2014; Delworth and Manabe 1988). In the LAND experiments, land-atmosphere coupling increased evapotranspiration (ET) variability, mainly for the midlatitudes $\left(30^{\circ}-60^{\circ} \mathrm{N}\right)$. There was also a slight increase in ET variability between $20^{\circ} \mathrm{S}$ and the equator.

Figure 2a also shows one ensemble member (gray line) from an experiment using the original GLACECMIP5 soil moisture seasonal climatology scheme in the LA-uncoupled ATM experiment, for which temperature variability decreased in the high latitudes $\left(60^{\circ}-\right.$ $80^{\circ} \mathrm{N}$ ). This decrease was entirely removed using the new scheme applied in this study.

The impact of land-atmosphere coupling shifted to the Southern Hemisphere during austral summer. Figure 3 shows the temperature and ET variability during the DJF season. Areas between $40^{\circ}$ and $10^{\circ} \mathrm{S}$ had increased temperature variance due to land-atmosphere coupling. ET variability did not change during the DJF season, perhaps because midlatitude inland areas are small in the Southern Hemisphere. Since stronger land-atmosphere coupling 

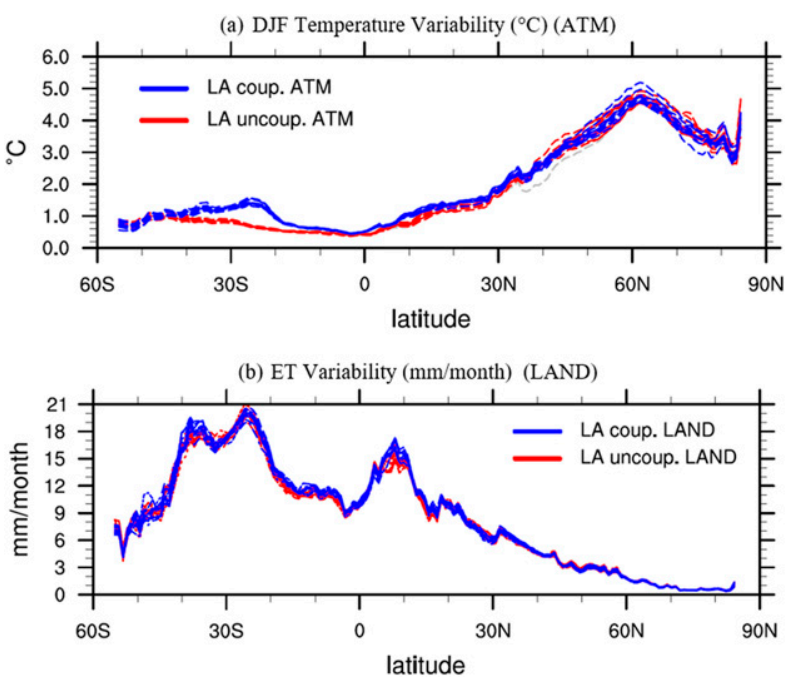

FIG. 3. As in Fig. 2, but for DJF.

effects were found during the JJA season, the remainder of the paper focuses on that season.

Different geographical regions show either increasing or decreasing ET variability responses due to landatmosphere coupling. Figure 4a shows the map of ET variability change (coupled minus uncoupled standard deviations), which significantly increased for $25 \%$ of the land area and decreased for $11 \%$ of the land area. Note that we show difference maps here with all analysis in dimensional units (e.g., mm month ${ }^{-1}$ for ET change) instead of showing relative change (e.g., percentage difference). Overall, landatmosphere coupling increases ET variability in the midlatitudes [e.g., central North America (CNA) and southern Europe and Eurasia (SEE)], as well as in subtropical regions [e.g., central Asia and parts of India (IND)], and certain regions in the Southern Hemisphere. In contrast, tropical regions [e.g., the northern part of the Sahel (SAH) and the Amazon and Congo basins] show decreased ET variability.

We next compare this spatial pattern of ET variability change with that of the precipitation variability change, shown in Fig. 4b, which significantly increased for $19 \%$ of the land area and decreased for $23 \%$ of the land area. Most of the increase in precipitation variability occurred in wet regions (e.g., the eastern United States, India, Southeast Asia, northeastern China, the northern part of the Congo, and north of the Amazon basins), while decreases occurred in dry regions (e.g., Sahel, Mediterranean Europe, the western United States, central Canada, South Africa, and the southern Amazon). Note that in the midlatitudes, significant changes of ET and precipitation variability generally did not coincide, suggesting that different climate processes drove these changes. Land-atmosphere interactions play a larger role in ET variability (Guo et al. (a) JJA ET variability change ( $\mathrm{mm} / \mathrm{month})$

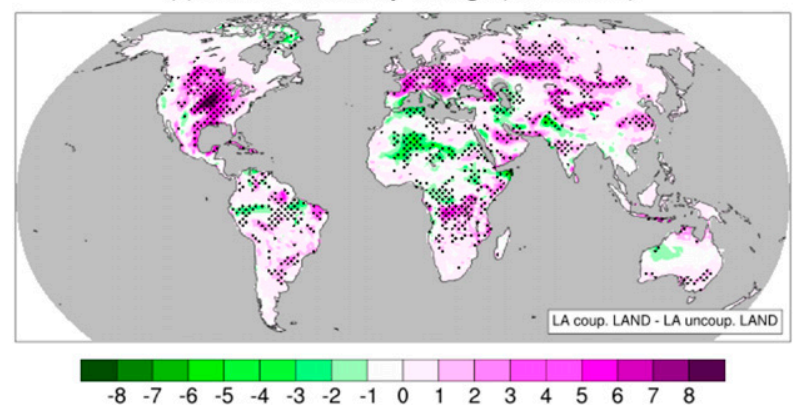

(b) JJA precipitation variability change ( $\mathrm{mm} / \mathrm{month})$

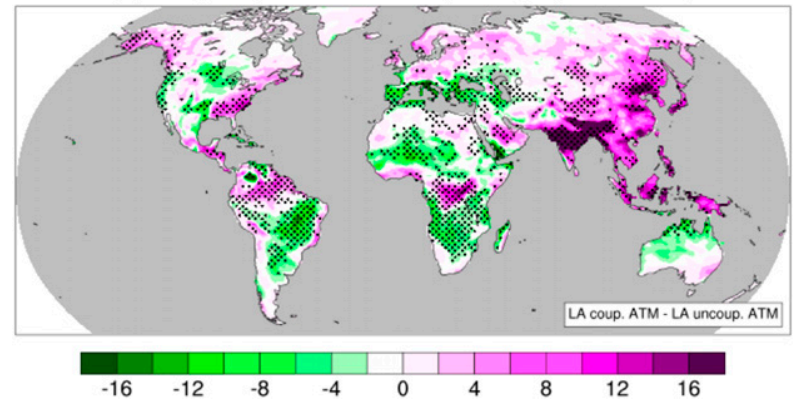

FIG. 4. Effects of land-atmosphere coupling on (a) evapotranspiration variability and (b) precipitation variability. The figure shows the difference between the LA-coupled and LA-uncoupled experiments and for the interannual standard deviation quantities averaged over the JJA months. Statistical significance of the difference at the $95 \%$ level is computed using the Monte Carlo method.

2012, 2006; Seneviratne et al. 2013), while circulation changes are likely to play a role in the precipitation variability. Further discussion of this issue is relegated to the appendix because we found that the precipitation variability change was not the primary driver of midlatitude soil moisture variability change due to land-atmosphere coupling.

An analysis similar to Fig. 4 for the DJF season, shown in Fig. S2, finds considerably reduced impacts due to the land-atmosphere coupling, consistent with Fig. 3.

\section{2) LAND-ATMOSPHERE INTERACTIONS}

The simultaneous correlation of soil moisture and ET anomalies $\rho_{\mathrm{ET}_{t} S_{t}}$ is one of the fundamental metrics used to assess land-atmosphere coupling (Dirmeyer 2011; Guo et al. 2006; Koster et al. 2006). As earlier found by Dirmeyer (2011), the LA-coupled LAND experiment (Fig. 5a) captures the spatial pattern of significant positive correlations in dry and transition regions, and negative correlations in wet regions. A negative $\rho_{\mathrm{ET}_{t} S_{t}}$ value might suggest that soil moisture anomalies are mainly driven by precipitation anomalies associated with increased cloud cover anomalies, thereby also reducing net radiation and consequently evapotranspiration (Tang and Leng 2013). 


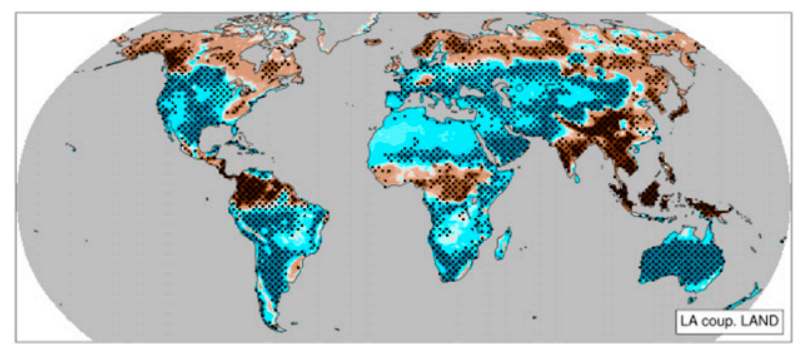

$\begin{array}{lllllllllllll}-0.6 & -0.5 & -0.4 & -0.3 & -0.2 & -0.1 & 0 & 0.1 & 0.2 & 0.3 & 0.4 & 0.5 & 0.6\end{array}$

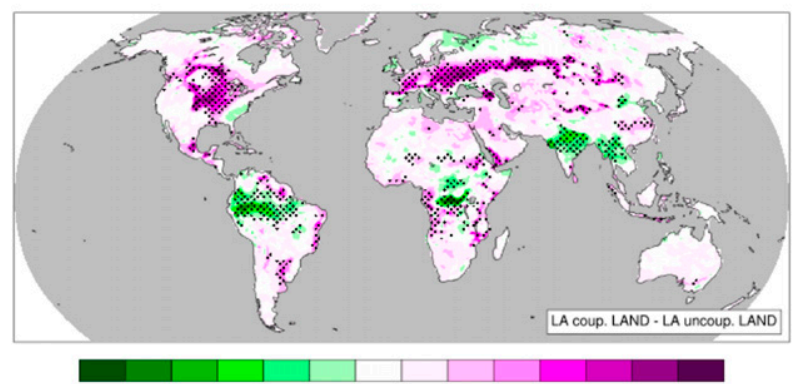

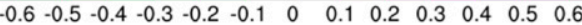

FIG. 5. Effects of land-atmosphere coupling on soil moisture and evapotranspiration (SM-ET) correlations. (top) The SM-ET correlations in the LA coupled LAND experiment and (bottom) its difference from the LA uncoupled LAND experiment using the dimensional unit. Statistical significance of the difference at the $95 \%$ level is computed using the Monte Carlo method.

The GLACE-Hydrology experiment has, for the first time, quantitatively assessed the effect of land-atmosphere coupling on the relationship between anomalous evapotranspiration and soil moisture. We found that coupling significantly amplified $\rho_{\mathrm{ET}_{t} S_{t}}$, both for positive correlations in the midlatitudes and negative correlations in the tropics (Fig. 5b), but only in some specific regions that somewhat (but not entirely) coincided with previously identified "hotspot" regions of land-atmosphere coupling (Koster et al. 2004). In central North America, southern Europe, and Eurasia, the differences were of the same order of magnitude as the total $\rho_{\mathrm{ET}_{t} S_{t}}$ values in the LA-coupled LAND experiment itself (Fig. 5). Elsewhere, including western North America, there was little change. We will come back to the western North America region in section $4 \mathrm{~d}$ to emphasize that soil moisture and ET covariability and their impact on soil moisture predictability are not spatially co-located. We repeated our analysis using the terrestrial coupling index metric developed by Dirmeyer (2011) and found similar results (Fig. S3).

\section{b. Land-atmosphere coupling effects on soil moisture variability and memory}

Land-atmosphere coupling increased soil moisture variability significantly for $18 \%$ of the land area, including parts of the central United States, central Asia, southern (a) JJA soil moisture variability change $(\mathrm{mm} / 3.8 \mathrm{~m})$

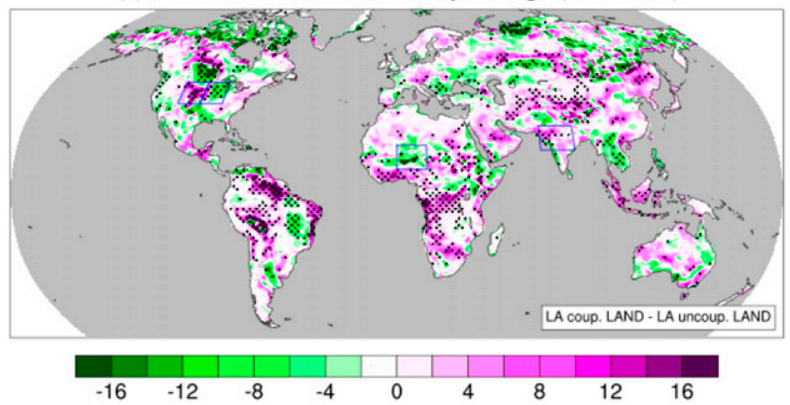

(b) JJA soil moisture memory change (lag1 correl.)

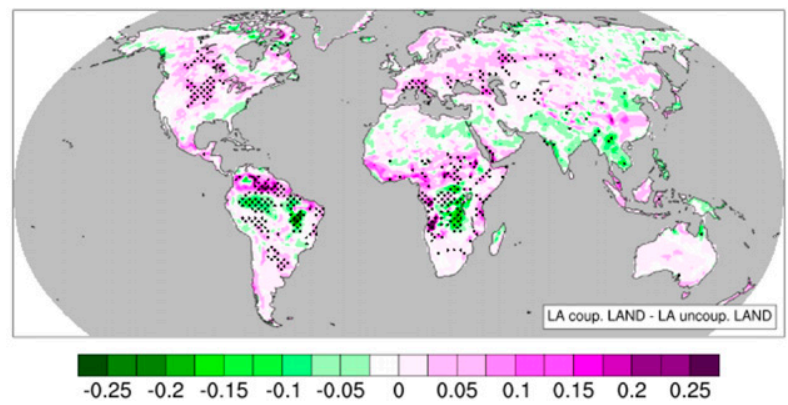

FIG. 6. Effects of the land-atmosphere coupling on the soil moisture variability and the memory. (a) The difference between the LA-coupled LAND and LA-uncoupled LAND JJA soil moisture interannual standard deviations ( $\mathrm{mm}$ of water in 3.8-m soil column). (b) The difference between soil moisture lag-1 autocorrelations between two experiments. Statistical significance of the difference at the $95 \%$ level is computed using the Monte Carlo method.

Sahel, and tropical regions of Africa, Asia, and South America, and decreased it for $11 \%$ of the land area, including parts of central North America, southern Europe, and Eurasia, and Southeast Asia (Fig. 6a). The changes were not consistent within any region, however, with significant increases and decreases often side by side, such as for the U.S. Midwest and its adjoining region to the east.

In contrast, differences in soil moisture memory $\rho_{S_{t} S_{t-1}}$ between the LA-coupled LAND and the LA-uncoupled LAND experiments (Fig. 6b) were spatially coherent. Land-atmosphere coupling increased soil moisture memory throughout most of the midlatitudes (significantly so for $12 \%$ of the land area), including central North America, southern Europe, and Eurasia. Note that these regions generally also showed an increase in ET variability (cf. Figs. $6 \mathrm{~b}$ and $4 \mathrm{a}$ ). Within the tropics, soil moisture memory decreased (significantly so for $7 \%$ of the land area), especially central Africa and the northern Amazon, due to changes in precipitation variability (to be discussed later).

\section{c. Components of soil moisture variability change due to land-atmosphere coupling}

Soil moisture variability change due to including land-atmosphere coupling (Fig. 6a) was not simply 


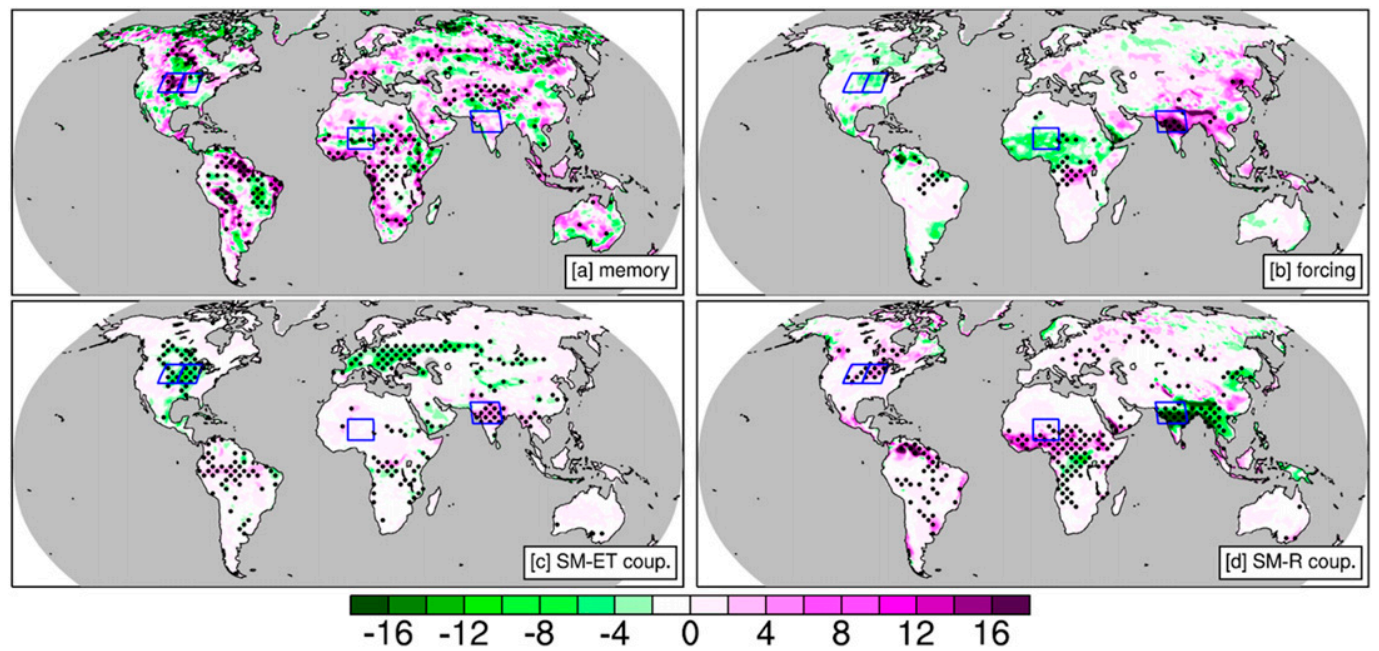

FIG. 7. Decomposition of the total soil moisture variability change by four driver climate processes: (a) the soil moisture memory, (b) the precipitation forcing, (c) SM-ET coupling, and (d) SM-R coupling (mm month ${ }^{-1}$ ).

balanced by change in any one term of Eq. (5). For example, in the midlatitudes, increased $\rho_{\mathrm{ET}_{t} s_{t}}$ values (Fig. 5b) did not always correspond to decreased soil moisture variability. Similarly, in some regions (e.g., India and the eastern United States), increased precipitation variability (Fig. 4b) corresponded to decreased soil moisture variability. Changes in soil moisture variability and precipitation variability were also of opposite signs in southern Africa and the southern Amazon basin. Overall, effects of land-atmosphere coupling on both moisture sources (precipitation) and/or sinks (evapotranspiration) as well as on $\rho_{\mathrm{ET}_{S} S_{t}}$ (Figs. 4 and 5b) were not sufficient to explain the soil moisture variability changes in the experiment, suggesting that changes in the other terms of Eq. (5), notably, soil moisture memory, must also have been important.

We therefore use Eq. (5) to diagnose how landatmosphere coupling drove the soil moisture variability changes seen in Fig. 6a. Figure 7 shows the corresponding changes in the four components of Eq. (5): soil moisture memory and the three terms representing the covariability of soil moisture (SM) with precipitation (SM-P), with evapotranspiration (SM-ET), and with runoff (SM-R). We first computed each of the four terms of (5) separately for the LA-coupled LAND and LAuncoupled LAND experiment for each month, and then we computed the difference between the coupled and uncoupled experiments. The statistical significance of the difference was computed using the Monte Carlo method. We multiplied each term by their sign in (5) so that the sum of all four panels in Fig. 7 equals Fig. 6a. It is worth noting that, even though these calculations used monthly data, the residual terms that result from not explicitly considering shorter time scales were very small (Fig. S5).
Change in the memory term $\rho_{S_{t} S_{t-1}} \sigma_{S_{t-1}}$ was the largest contributor to increased soil moisture variability in many regions (Fig. 7a), especially where driven by a lengthening of the memory $\rho_{S_{t} S_{t-1}}$ (cf. Fig. 6b); that is, an increase in persistence occurred, which may be expected to lead to greater variability, all else being equal. The change in the SM-P covariability term was primarily due to change in precipitation variability $\sigma_{P_{t}}$, since $\rho_{P_{t} S_{t}}$ did not change significantly (Fig. S4), so the term $\sigma_{P_{t}} \times \rho_{P_{t} S_{t}}$ may also be considered as the "forcing" term. However, the change in this term led to surprisingly little change in soil moisture variability, apart from some regions in and near the tropics (India and central Africa; Fig. 7b), perhaps because the effects of land-atmosphere coupling on ET variability and on precipitation variability were not spatially co-located (Fig. 4) and so acted somewhat to offset each other, with the notable exception of over India. This suggests that previous land-only/ hydrology only experiments (e.g., Livneh and Hoerling 2016; Luo et al. 2017; Williams et al. 2015) that, by design, assumed coincident precipitation variability and land-atmosphere coupling/ET variability changes may have overestimated precipitation impacts on soil moisture droughts.

Strengthened SM-ET covariability mainly contributed to decreasing soil moisture variability in the midlatitudes, including central North America and southern Europe and Eurasia (Fig. 7c), and generally tended to oppose the increase from the memory term. Recall that both $\rho_{\mathrm{ET}_{t} S_{t}}$ and ET variability also increased in these regions (cf. Fig. 7c with Figs. 4a and 5). SM-ET covariability increased soil moisture variability in the tropical regions, including India and the northern Amazon basin, 


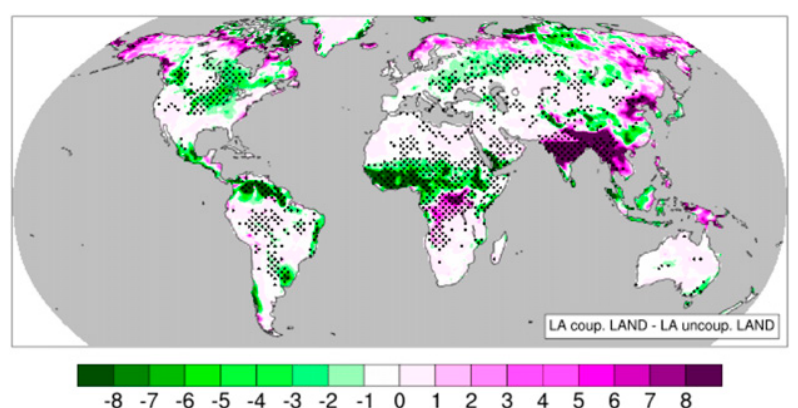

FIG. 8. Effects of the land-atmosphere coupling on total runoff variability $\left(\mathrm{mm} \mathrm{month} \mathrm{m}^{-1}\right)$. The figure shows the difference between the LA-coupled LAND and LA-uncoupled LAND JJA total runoff interannual standard deviations ( $\mathrm{mm}$ of water in $3.8 \mathrm{~m}$ soil column). Statistical significance of the difference at the $95 \%$ level is computed using the Monte Carlo method.

also as expected because $\rho_{\mathrm{ET}_{t} S_{t}}$ was negative in wet regions (Fig. 5b).

Changes in SM-R covariability, which in general (and not surprisingly) opposed changes in SM-P covariability, contributed to an increase in soil moisture variability in the transition region (e.g., parts of central North America and the Sahel) and a decrease in the wet region (e.g., India and
Southeast Asia) (Fig. 7d). We investigated the SM-R correlation $\rho_{R_{t} S_{t}}$ and runoff variability $\sigma_{R_{t}}$ separately. We found that the runoff variability significantly decreased due to landatmosphere coupling in the transition region and increased in the wet region (Fig. 8), whereas the $\rho_{R_{t} S_{t}}$ did not change significantly (Fig. S6). In other words, SM-R covariability mainly changed due to changes in the runoff variability.

A physically plausible explanation for how coupling changed the runoff term might be the following: SM-R covariability increased soil moisture variability in the transition regions by slowing water drainage from the soil and therefore decreasing runoff variability. SM-R covariability decreased soil moisture variability in the wet regions because of reduced infiltration due to saturated conditions and, therefore, a higher partitioning of precipitation into runoff than into the soil, and therefore an increase in the runoff variability (Niu et al. 2005).

There was strong regional dependence in how these four terms together balanced the soil variability. Figure 9 shows the regional contributions of the memory, forcing, SM-ET covariability, and SM-R covariability terms averaged within two midlatitude regions, the Midwest (MW-U.S.) and the central eastern (CE-U.S.) United States, and two lowlatitude regions, the central west Sahel $(\mathrm{CW}-\mathrm{SAH})$ and
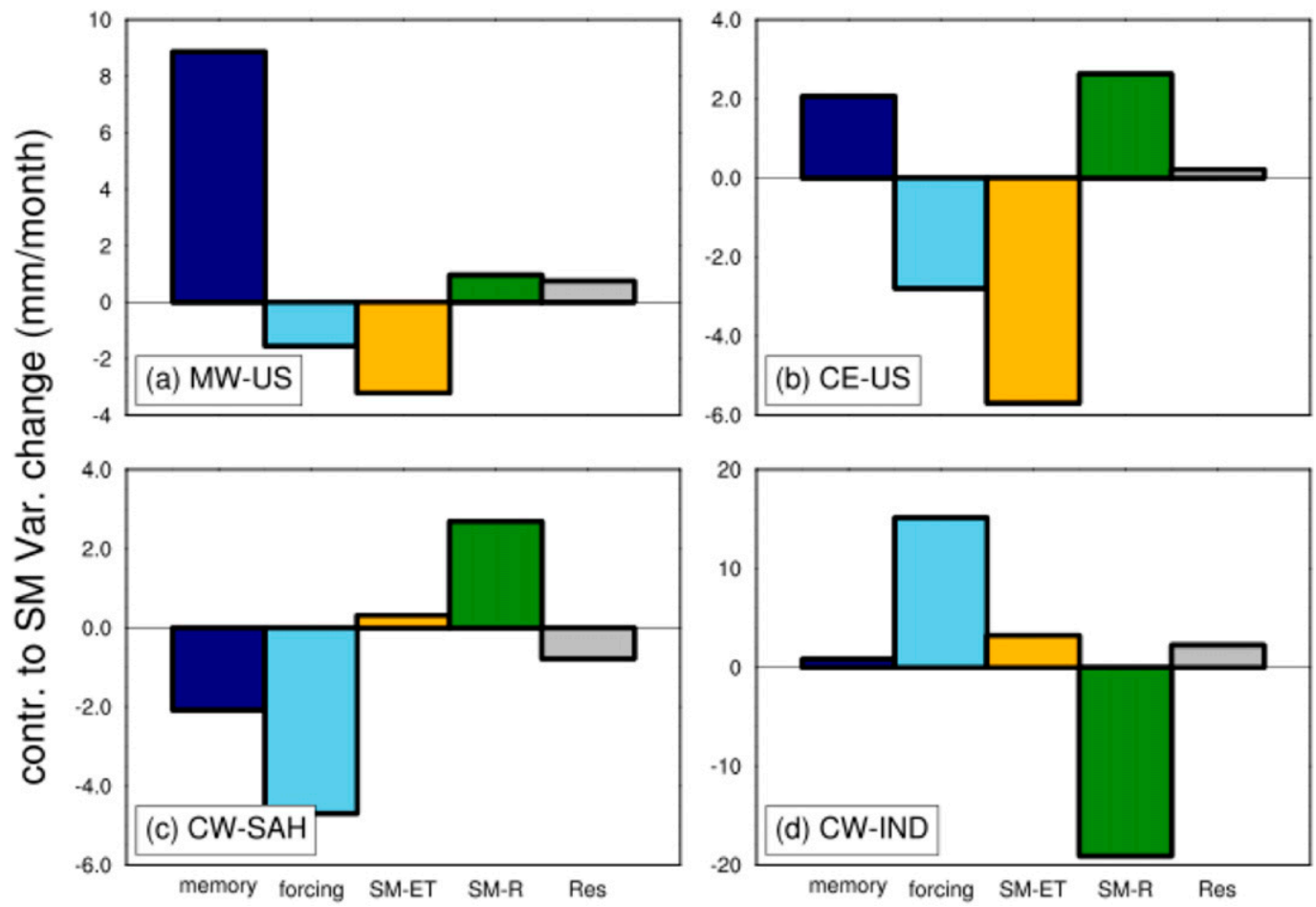

FIG. 9. Area average contributions of the memory, forcing, SM-ET, and SM-R coupling terms [Eq. (5)] to the soil moisture variability change due to land-atmosphere coupling in the GLACE-Hydrology experiment. The residual term (Res) is computed as the difference between total variability change (Fig. 6a) minus the sum of the four terms shown in Fig. 7. The four regions shown are the Midwest (MW-U.S.), the central-east United States (CE-U.S.), the central-west Sahel (CW-SH), and central-west India (CW-IND); these regions refer to four boxes shown in Fig. 7. 
Precipitation (JJA)

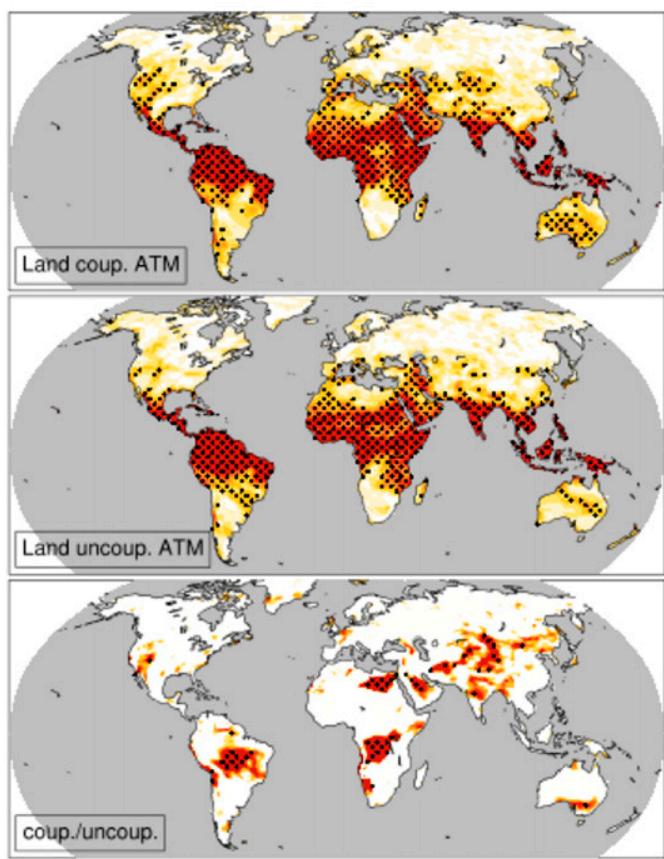

Root zone soil moisture (JJA)

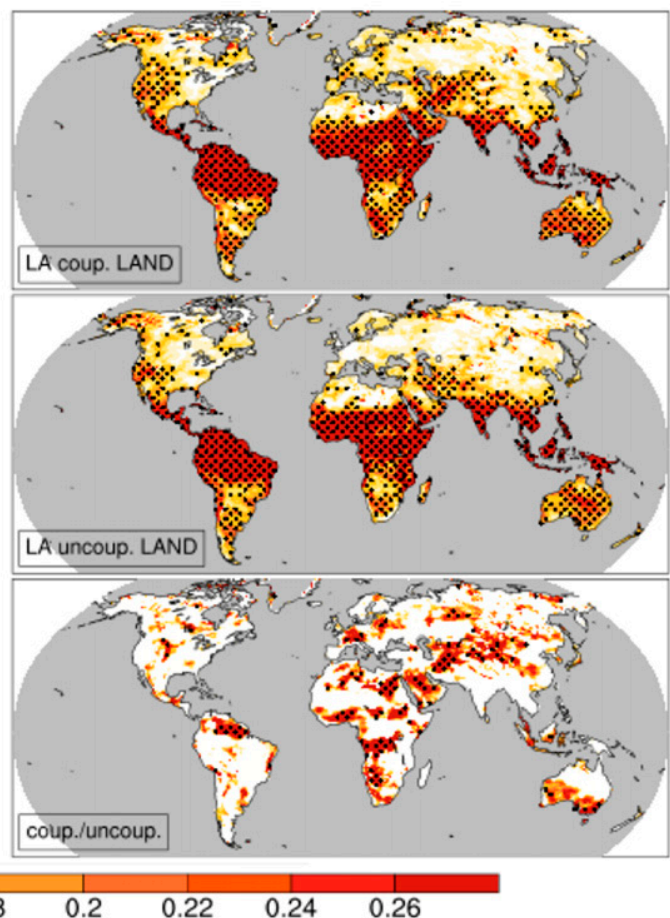

FIG. 10. Effects of land-atmosphere coupling on potential predictability of (left) precipitation and (right) root zone soil moisture for the boreal summer (JJA) in the GLACE-Hydrology experiments. The signal-to-total ratio in the (top) LA coupled and (middle) LA uncoupled experiments. (bottom) The log of the ratio of LA coupled and LA uncoupled signals, which indicates where potential predictability increases due to land-atmosphere coupling. Statistical significance at $95 \%$ level are shown using stippling. See the text for details.

central west India (CW-IND). In the MW-U.S., the increased memory term largely contributed to increased soil moisture variability. The relative influence of the SM-ET coupling term was negative and $\sim 3$ times smaller than that of memory term. In the CE-U.S., on the other hand, it was reduced SM-ET covariability that largely contributed to decreased soil moisture variability.

In the tropical/subtropical regions, change to the forcing term played a larger role, although change to SM-R covariability generally counterbalanced it. For example, the forcing term increased soil moisture variability in CW-IND by making it wetter (see the appendix), but it was balanced by the SM-R covariability, resulting in only a small increase in soil moisture variability. Similarly, in CW-SAH, decreased forcing variability was balanced by increased SM-R covariability, resulting in a smaller net decrease in soil moisture variability that seems to be contributed by the decrease in the memory term (Fig. 7a). While SM-ET covariability, which has also sometimes been referred to as the SM-ET coupling term, has received more attention in previous GLACE studies (Dirmeyer 2011; Guo et al. 2006; Koster et al. 2004, 2006), Fig. 9 shows that changes to the memory term and SM-R covariability played an equally important role in coupling impacts on soil moisture variability. This is the second unique contribution of the inclusion of the land-only simulations in the GLACE-Hydrology experiment.

\section{d. Implications for seasonal hydroclimate potential predictability}

Finally, we show that land-atmosphere coupling enhanced SST-forced hydroclimate potential predictability in many areas of the globe. Figure 10 compares the JJA STR for precipitation (left column) and root zone soil moisture (right column) between the LA coupled and LA uncoupled experiments. The coupled experiment had a statistically significant precipitation signal covering $50 \%$ of the land area $\left(60^{\circ} \mathrm{S}-80^{\circ} \mathrm{N}\right)$, a small increase over the $46 \%$ land coverage in the LA uncoupled experiment. The landatmosphere coupling also significantly improved precipitation predictability for $8 \%$ of the land area. Notably, coupling enhanced the statistically significant predictable precipitation signal in western North America and Australia.

Anomalous soil moisture was more predictable than anomalous precipitation and was also more enhanced by coupling. The LA coupled and uncoupled experiments 
showed a statistically significant signal for $62 \%$ and $58 \%$ of the global land area, respectively. Western North America had a higher areal coverage of statistically significant soil moisture predictability signal in the LA coupled experiment. Many portions of central Europe (e.g., France) showed a statistically significant predictable signal, which was almost missing in the LA uncoupled experiments. Improvement was also evident for portions of central Asia and Africa. Overall, the land-atmosphere coupling significantly improved soil moisture predictability for $15 \%$ of the global land area.

\section{Summary and discussion}

We performed a new GLACE-Hydrology Experiment to elucidate the role of land-atmosphere coupling on soil moisture variability and predictability. A unique contribution of the experiment is the quantitative assessment of how this coupling impacts the correlation between soil moisture and evapotranspiration, by comparing the coupled and uncoupled experiments using land-only simulations in stage 2 . The land-atmosphere coupling enhances the amplitude of SM-ET correlations significantly, especially in transition regions where atmospheric variability drives a mean summertime moisture source (i.e., mean ET $>$ mean precipitation) from land into the atmosphere in North America, Europe, and Asia (Newman et al. 2012). It is worth noting that the soil moisture and ET were evolving interactively in both the LA-coupled and LA-uncoupled LAND experiments (stage 2 in Fig. 1), but they received different atmospheric forcing: one from the LA-coupled ATM and the other from the LA-uncoupled ATM experiment, respectively (Fig. 1). That is, the difference between the two experiments is directly attributable to the climate forcing data. This new result has at least one important implication: landatmosphere coupling has a signature that can be detected in land forcing fields. That is, if several different land surface models are driven with the same climate forcing data, then these land surface models may show similar SM-ET correlations. And vice versa, if the same land surface model is driven with two different climate forcing data, they may show different SM-ET correlations, as is the case in this study.

A robust finding from the GLACE-Hydrology experiment is that the land-atmosphere coupling increases soil moisture memory in the midlatitudes during boreal summer (Fig. 6b). We have not yet determined the mechanism by which this occurred in the model experiments. However, it is interesting to note that this increase generally coincided with an increase both in ET variability and in $\rho_{\mathrm{ET}_{t} s_{t}}$. The land generally acts to moisten the lower atmosphere in the midlatitudes during boreal summer (see appendix and Fig. A4), since evapotranspiration exceeds precipitation so that the land acts as a net source of moisture to the atmosphere (Kumar et al. 2014a; Sheffield et al. 2013). Following Darcy's law, the rate of moisture exchange between land and atmosphere will decrease (see the appendix and Fig. A5). As a result, we may expect that the soil moisture anomaly will revert more slowly toward the climatological mean, and therefore land-atmosphere coupling increases the soil moisture memory.

In essence, we are proposing that, in regions where the land surface provides moisture to the atmosphere (i.e., midlatitudes during summertime), land-atmosphere coupling may act to reduce the damping rate of soil moisture anomalies. This hypothesis is similar to the one proposed by Barsugli and Battisti (1998) to explain the basic effect of ocean-atmosphere thermal coupling in the midlatitudes: Coupling between atmosphere and ocean should decrease the energy flux between them, providing a "reduced thermal damping" that effectively lengthens the memory time scales and therefore the temperature variability in both systems. Similarly, the basic effect of land-atmosphere coupling is to decrease the moisture exchange between the land surface and atmosphere (see appendix and Fig. A5), effectively increasing the memory and variability of soil moisture. Clearly, this is a substantial simplification of the land-atmosphere coupling response; just as for oceanatmosphere coupling, there should be a dependence on horizontal and vertical scales of atmospheric transport and mixing, not to mention nonlocal atmospheric responses to nonlocal surface anomalies, which all likely impact precipitation as well. Also, there are additional complexities involved in land-atmosphere interaction processes, such as limited water availability over land, and as land becomes drier it offers further resistance to moisture fluxes (Kumar et al. 2015, 2013, 2016). A similar hypothesis can be proposed for vegetation interactions that offer an additional layer of resistance for moisture exchange between land and atmosphere (Bonan 2016).

The increased soil moisture memory due to landatmosphere coupling can improve hydroclimate predictability in the midlatitude regions. Our study found statistically significant improvments in the potential predictability of precipitation and soil moisture. This impact is greater for soil moisture than precipitation (Fig. 10). A similar analysis can be extended to identify how the predicted evolution of individual droughts is impacted by land-atmosphere coupling.

A multimodel analysis is needed to develop a more comprehensive diagnosis of the role of land-atmosphere coupling in soil moisture predictability. Model spatial resolution and convective parameterizations also play an important role in precipitation triggering due to soil wetness and its heterogeneity (Holgate et al. 2019; Hsu et al. 2017; Taylor et al. 2013). Multimodel data from Land 
Surface Snow and Soil Moisture Model Intercomparison Project and phase 6 of the Coupled Model Intercomparison Project (CMIP6) AMIP-type experiments can possibly be used (Eyring et al. 2016; van den Hurk et al. 2016). However, these experiments do not include the hydrology part of the experiment. We are also aware that single forcing large ensemble experiments are currently underway at NCAR and also possibly a few other institutions (C. Deser, NCAR, 2019, personal communication). We hope that this study provides sufficient motivation to include landatmosphere coupling as a major parameter to understand hydroclimate variability and predictability. From our experience, running the hydrology part (stage 2 ) of the simulation is data intensive (saving the 3-hourly data), but the process can be automated if sufficient motivation is found.

This study may also provide an upper limit on the potential predictability of droughts in the Community Earth System Modeling framework. Operational forecast skill is likely to be lower than the potential predictability estimated by this study (e.g., Dirmeyer et al. 2018; Murphy and Epstein 1989). Many operational forecasting systems (e.g., the Climate Forecast System version 2 and North American Multi-Model Ensemble seasonal forecasting system) include land-atmosphere coupling in their forecast (Kirtman et al. 2014; Saha et al. 2010). However, there are considerable uncertainties in the representation of the land-atmosphere coupling and soil moisture memory in the seasonal forecasting models (Dirmeyer 2013; Dirmeyer and Halder 2017; Dirmeyer et al. 2016; Roundy et al. 2014; Santanello et al. 2015). Recently, the availability of in situ and remotely sensed soil moisture data (Entekhabi et al. 2014; Quiring et al. 2016) has provided the opportunity to improve the process-level representation of soil hydrology, as well as to develop methodology incorporating observationally constrained soil moisture initial conditions into the seasonal forecast (e.g., Duan and Kumar 2020).

Overall, this study demonstrates a new pathway, via soil moisture memory, through which land-atmosphere coupling can impact soil moisture variability and drought predictability. The soil moisture memory pathway acts in concert with the soil moisture and evapotranspiration interaction pathways that have been extensively investigated in previous GLACE studies (Dirmeyer 2011; Guo et al. 2006; Koster et al. 2006). Hence, this study provides new knowledge about the effects of land-atmosphere coupling on land variability.

Acknowledgments. This work was primarily supported by National Research Associateship Award to the first author at NOAA Earth System Research Laboratory, Boulder, CO. Additional funding support was provided by the USDA Hatch Grant ALA031-1-18023. The CESM project is supported primarily by the National Science Foundation (NSF). This material is based upon work supported by the National (a) JJA soil moisture mean difference ( $\mathrm{mm}$ water in $3.8 \mathrm{~m}$ soil column)

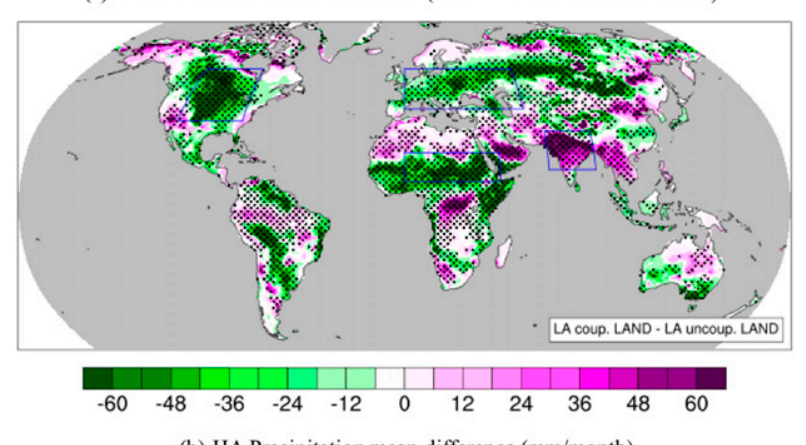

(b) JJA Precipitation mean difference ( $\mathrm{mm} / \mathrm{month})$

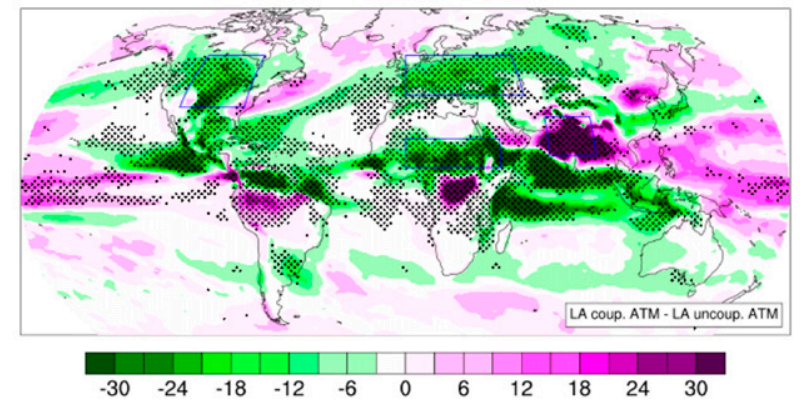

FIG. A1. Effects of land-atmosphere coupling on JJA mean soil moisture and precipitation.

Center for Atmospheric Research, which is a major facility sponsored by the NSF under Cooperative Agreement 1852977. DML is supported by the U.S. Department of Energy, Office of Biological and Environmental Research Grant DE-FC03-97ER62402/A0101, and the National Institute of Food and Agriculture Grant 201567003-23489. Min-Hui Lo and Chia-Wei Lan were supported by the MOST Grant 106-2111-M-002-010-MY4 to the National Taiwan University. The first author thanks Paul Dirmeyer (George Mason University), for his input on the GLACE-Hydrology experiment design. We would like to acknowledge high-performance computing support from Cheyenne (https://doi.org/10.5065/D6RX99HX) provided by NCAR's Computational and Information Systems Laboratory, sponsored by the National Science Foundation. The experiment data are available upon request to the first author because data size is too large (20 TB). We intend to make the data on NCAR Research Data Archive available upon acceptance. The first author also thanks Yanan Duan (Auburn University) for her help in plotting Fig. A2.

\section{APPENDIX}

\section{Changes in Mean Climate}

We presented an extensive discussion on soil moisture variability change and its drivers in the main text. It is worth looking at how the mean climate changed and if 

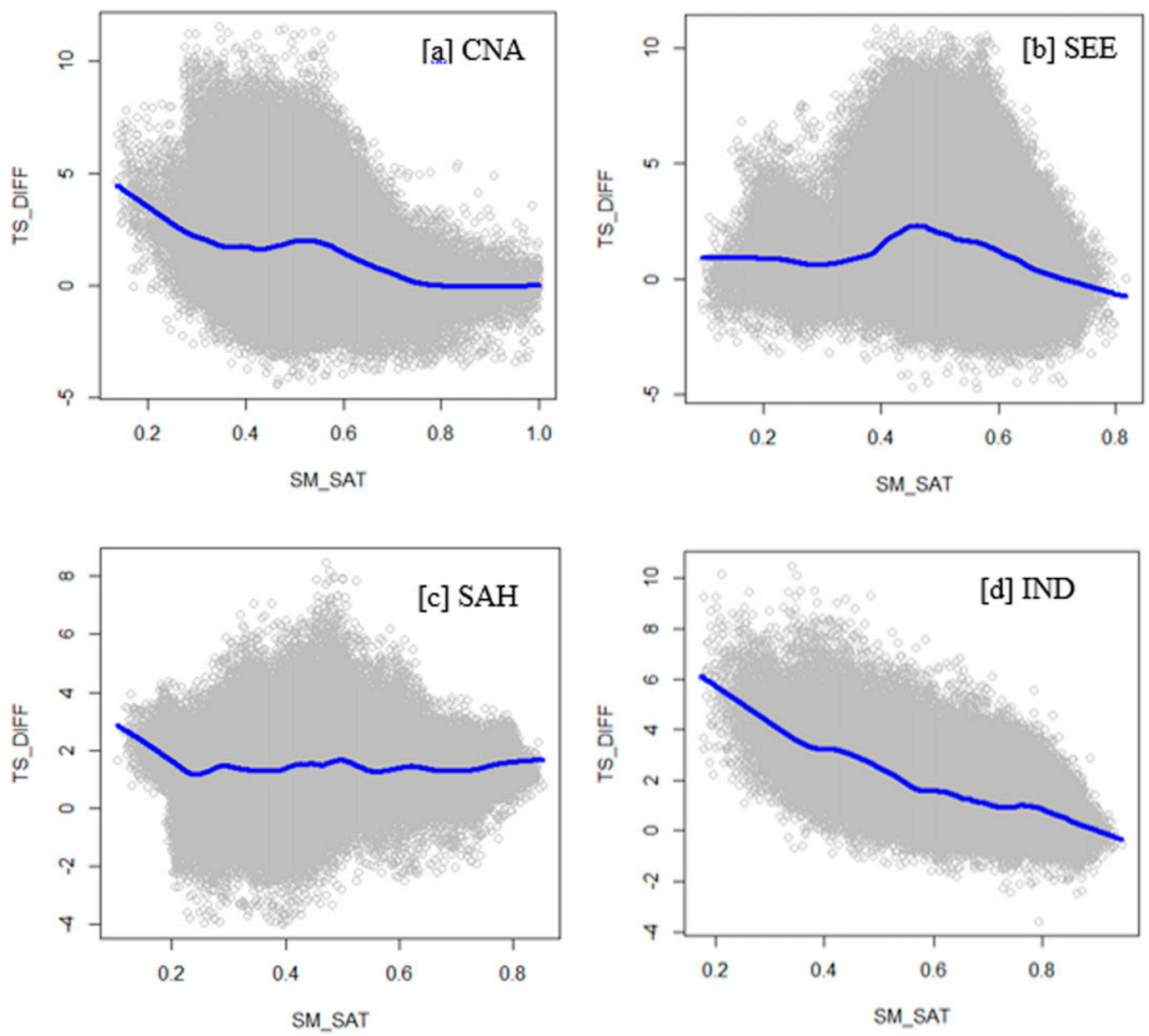

FIG. A2. Asymmetric response of the land model to the land-atmosphere coupling (i.e., land responds strongly during dry years compared to wet years). The figure shows soil moisture saturation (SM_SAT) fraction from the LA coupled ATM experiment on the $x$ axis, and surface-level air temperature difference (TS_DIFF) in ${ }^{\circ} \mathrm{C}$ between the LA coupled ATM and LA uncoupled ATM experiments on the $y$ axis in four regions: (a) central North America (CNA), (b) southern Europe and Eurasia (SEE), (c) the Sahel (SAH), and (d) India (IND) for the JJA. These regions are shown in Fig. A1. Each data point shows each grid and year (1979-2014) in the respective region (see text). Soil saturation level is from the root zone average $(0-1 \mathrm{~m})$. The thick blue line shows locally weighted polynomial regression using the "lowess" function in R.

these changes affected the results. In short, we found that while the mean climate changed it did not significantly affect the soil moisture variability through the forcing term (Figs. 7 and 9) or our principal results. We will show in this section that soil moisture mean climate change appears to be driven by the circulation change due to land-atmosphere coupling. The statistical significance of the difference in multi-ensemble and multiyear mean is computed using a signal-to-noise metric as described by Kumar et al. (2014b).

\section{a. Changes in JJA mean soil moisture and precipitation}

Figure A1 shows that the boreal summer mean soil moisture changes between the LA-coupled and LA-uncoupled
LAND experiments are globally extensive and statistically significant, and are of both positive and negative signs. The land-atmosphere coupling caused significant drying in central North America (CNA), southern Europe and Eurasia (SEE), and the Sahel (SAH), and wetting in India (IND), parts of the Congo basin in central Africa, and northwestern parts of the Amazon basin.

The soil moisture response follows the precipitation response globally (Fig. A1b), with midlatitude drying in central North America, southern Europe, and Eurasia, and wetting in the tropics, including India, the Congo basin, and the southern Amazon. The Sahel became drier. Midlatitudes in much of the Southern Hemisphere also become drier, but these regions have overall smaller precipitation during JJA (not shown). 

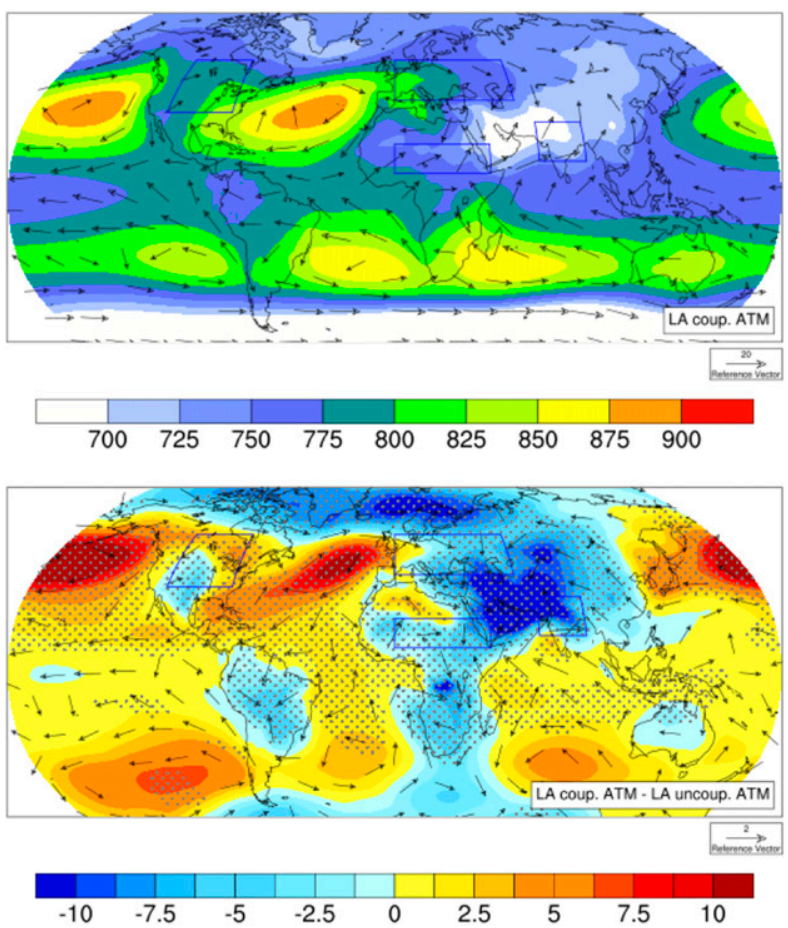

FIG. A3. Effects of land-atmosphere coupling on 925-hPa geopotential height and wind in JJA. The reference wind vector represents $20 \mathrm{~m} \mathrm{~s}^{-1}$ in the top panel and $2 \mathrm{~m} \mathrm{~s}^{-1}$ in the bottom panel.

Figure A1b also shows statistically significant precipitation changes over the ocean. We see global circulation features in the precipitation changes with a general drying in subtropical dry zones, including the midlatitude North Atlantic and the U.S. west coast Pacific Rim, and wetter conditions in tropical convergence zone. Drying in the Indian Ocean can be related to the stronger monsoon circulation in which more low-level water vapor is transported to the Indian subcontinent from the Indian Ocean. The monsoonal flow then returns southward at high-level troposphere and subsides over the Indian Ocean region, e.g., (Wey et al. 2015). In other words, land-atmosphere coupling can induce an intensified summer monsoonal circulation and local Hadley cell.

\section{b. Why did circulation change due to land-atmosphere coupling?}

Soil moisture variability affects the partitioning of net radiation into latent and sensible heat fluxes, thereby increasing surface temperature variability (Berg et al. 2014; Delworth and Manabe 1988; Kumar et al. 2010) (Fig. 2). Previous studies have also found that land-atmosphere coupling increases mean surface temperature (Berg et al. 2014), which is also supported by regional studies over North America

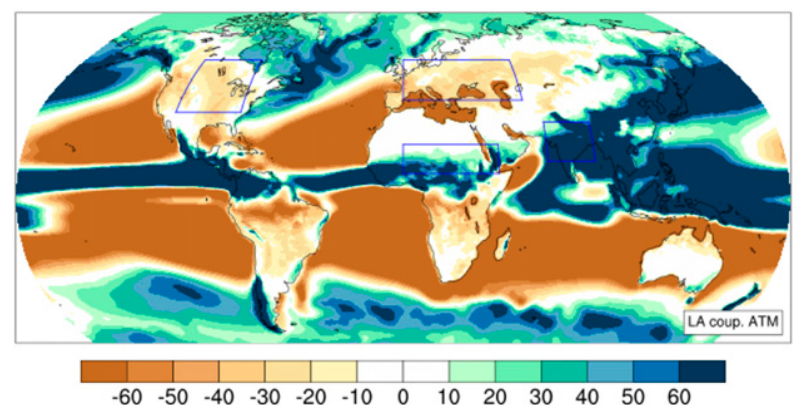

FIG. A4. Wet $(P-$ ET $>0)$ and dry regions $(P-$ ET $<0)$ in the JJA season. The figure shows $P-$ ET climatology $\left(\mathrm{mm} \mathrm{month}^{-1}\right)$.

(Teng et al. 2019). But the reason behind this change is less understood.

Under the drier conditions, the land responds strongly with increased surface temperatures. This response is muted under wet conditions, yielding an overall warming response as a result of land-atmosphere coupling (Fig. S1). Figure A2 shows the difference in near-surface air temperature between the LA-coupled ATM and LAuncoupled ATM experiments for each year and in the four regions outlined earlier. These differences are plotted against the corresponding soil wetness in the LA coupled ATM experiment in the JJA season. Note that by construction there is no change in mean soil moisture between the two experiments. Land response is asymmetric to the surface wetness conditions in all four regions. In other words, land responds strongly during dry years by limiting available moisture for evapotranspiration and thereby increasing the surface temperature, but land acts as the receiver of the climate forcing in the wet conditions. This notion is also supported by Guo and Dirmeyer (2013), who found that interannual variability land-atmosphere coupling is modulated due to surface wetness conditions.

Increased surface temperatures affect surface pressure anomalies between land and ocean, thereby inducing circulation anomalies that propagate into upper atmospheric levels (e.g., Koster et al. 2016; Teng et al. 2019). Figure A3 shows geopotential heights and wind at $925 \mathrm{hPa}$. Negative anomalous $925-\mathrm{hPa}$ geopotential heights corresponding to the lower surface pressure are present over most continental areas, while there are positive anomalies over the northern Pacific and Atlantic. Miyasaka and Nakamura (2005) used a numerical model to demonstrate the critical role of land-sea thermal contrast for the formation and maintenance of the Northern Hemisphere summertime subtropical highs, as also suggested by Wu and Liu (2003), Liu et al. (2004), and Seager et al. (2003). Thus, the stronger subtropical high over the Atlantic and Pacific Oceans could be related to the enhancement of near-surface thermal 


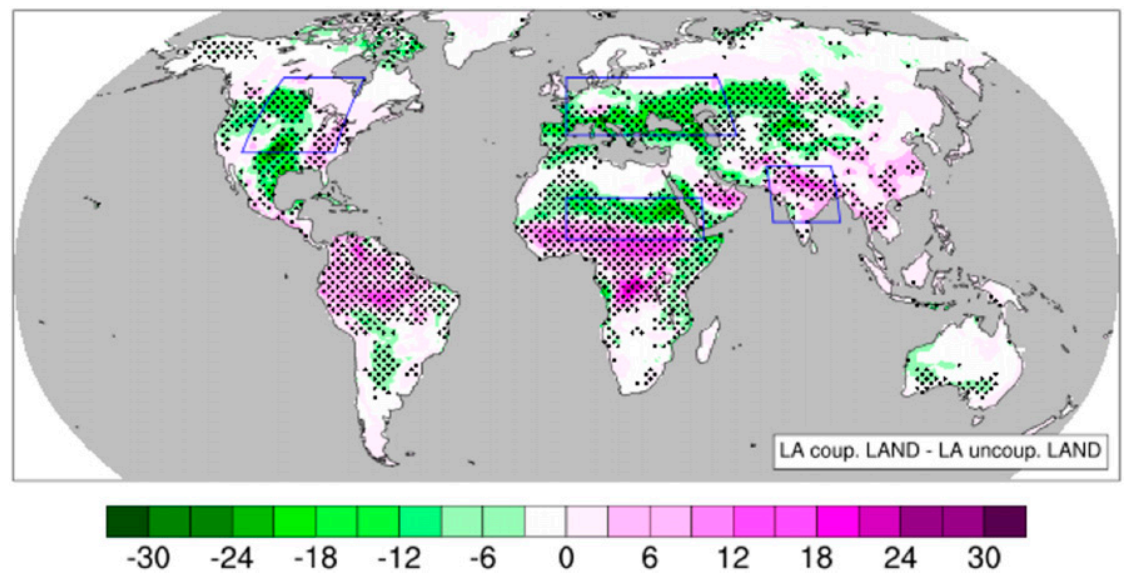

FIG. A5. Effects of land-atmosphere coupling on mean ET in the JJA season (mm month $\left.{ }^{-1}\right)$.

contrasts in the eastern oceans, owing to warming over the land due to land-atmosphere coupling.

Figure A4 shows the climatological precipitation minus evapotranspiration $(P-\mathrm{ET})$ analysis in the LA coupled ATM experiment and for the boreal summer season. The $P-$ ET map shows net atmospheric moisture sources and sinks, with positive (negative) $P-$ ET representing vertically integrated moisture flux convergence (divergence). Both CNA and SEE regions are net moisture divergence regions during the boreal summer, and both regions become additionally drier due to landatmosphere coupling (Fig. A1). India is a net moisture convergence region that becomes wetter due to landatmosphere coupling. A similar response is also seen over the North Atlantic and Pacific subtropical dry zones (negative $P-\mathrm{ET}$ ), where drying enhances at the edges of the deep dry zones. Sahel represents a diverging region toward its northern boundary, and converging region toward the southern boundary, and shows an overall drying response (Fig. A1). Thus, the first-order response in the summer hemisphere to land-atmosphere coupling is consistent with the "wet-gets-wetter and drygets-drier" paradigm (Held and Soden 2006; Kumar et al. 2015). There is an exception in the winter hemisphere (e.g., southern Amazonia in South America and the central Congo basin in Africa). Overall, we conclude that the circulation changes drove the mean precipitation changes that affected the mean soil moisture climate (Fig. A1).

\section{c. Effects on moisture flux from land to atmosphere}

Land-atmosphere coupling decreases mean evapotranspiration in the midlatitude regions, including central North America, southern Europe, central Asia, and northern parts of Sahel (Fig. A5). A statistically significant reduction in mean ET is found in the regions where $\rho_{\mathrm{ET}_{t} S_{t}}$ is positive (Fig. 5a). Tropical regions, including
India, central Asia, and the Amazon, show a significant increase in mean ET; these regions also have negative soil moisture and ET correlations (Fig. 5a). Overall, Fig. A5 supports the hypothesis postulated in the discussion section that land-atmosphere coupling decreases moisture flux from land to atmosphere in the midlatitudes.

\section{REFERENCES}

Amenu, G. G., P. Kumar, and X. Z. Liang, 2005: Interannual variability of deep-layer hydrologic memory and mechanisms of its influence on surface energy fluxes. J. Climate, 18, 50245045, https://doi.org/10.1175/JCLI3590.1.

Ault, T. R., S. St. George, J. E. Smerdon, S. Coats, J. S. Mankin, C. M. Carrillo, B. I. Cook, and S. Stevenson, 2018: A robust null hypothesis for the potential causes of megadrought in western North America. J. Climate, 31, 3-24, https://doi.org/ 10.1175/JCLI-D-17-0154.1.

Barsugli, J. J., and D. S. Battisti, 1998: The basic effects of atmosphere-ocean thermal coupling on midlatitude variability. J. Atmos. Sci., 55, 477-493, https://doi.org/10.1175/15200469(1998)055<0477:TBEOAO > 2.0.CO;2.

Berg, A., B. R. Lintner, K. L. Findell, S. Malyshev, P. C. Loikith, and P. Gentine, 2014: Impact of soil moisture-atmosphere interactions on surface temperature distribution. J. Climate, 27, 7976-7993, https://doi.org/10.1175/JCLI-D-13-00591.1.

Bonan, G. B., 2016: Ecological Climatology: Concepts and Applications. 3rd ed. Cambridge University Press, 692 pp.

— , K. W. Oleson, M. Vertenstein, S. Levis, X. Zeng, Y. Dai, R. E. Dickinson, and Z.-L. Yang, 2002: The land surface climatology of the Community Land Model coupled to the NCAR Community Climate Model. J. Climate, 15, 3123-3149, https://doi.org/10.1175/ 1520-0442(2002)015<3123:TLSCOT>2.0.CO;2.

Cheng, L. Y., M. Hoerling, A. AghaKouchak, B. Livneh, X. W. Quan, and J. Eischeid, 2016: How has human-induced climate change affected California drought risk? J. Climate, 29, 111120, https://doi.org/10.1175/JCLI-D-15-0260.1.

Dahlin, K. M., R. A. Fisher, and P. J. Lawrence, 2015: Environmental drivers of drought deciduous phenology in the Community Land Model. Biogeosciences, 12, 5061-5074, https://doi.org/ 10.5194/bg-12-5061-2015. 
Delworth, T. L., and S. Manabe, 1988: The influence of potential evaporation on the variabilities of simulated soil wetness and climate. J. Climate, 1, 523-547, https://doi.org/10.1175/15200442(1988)001<0523:TIOPEO > 2.0.CO;2.

de Noblet-Ducoudré, N., and Coauthors, 2012: Determining robust impacts of land-use-induced land cover changes on surface climate over North America and Eurasia: Results from the first set of LUCID experiments. J. Climate, 25, 3261-3281, https://doi.org/10.1175/JCLI-D-11-00338.1.

Dirmeyer, P. A., 2011: The terrestrial segment of soil moistureclimate coupling. Geophys. Res. Lett., 38, L16702, https:// doi.org/10.1029/2011GL048268.

_ 2013: Characteristics of the water cycle and land-atmosphere interactions from a comprehensive reforecast and reanalysis data set: CFSv2. Climate Dyn., 41, 1083-1097, https://doi.org/ 10.1007/s00382-013-1866-x.

_ - and S. Halder, 2017: Application of the land-atmosphere coupling paradigm to the operational Coupled Forecast System, version 2 (CFSv2). J. Hydrometeor., 18, 85-108, https://doi.org/10.1175/JHM-D-16-0064.1.

_ - R. D. Koster, and Z. C. Guo, 2006: Do global models properly represent the feedback between land and atmosphere? J. Hydrometeor., 7, 1177-1198, https://doi.org/10.1175/JHM532.1.

— S. Kumar, M. J. Fennessy, E. L. Altshuler, T. DelSole, Z. Guo, B. A. Cash, and D. Straus, 2013: Model estimates of land-driven predictability in a changing climate from CCSM4. J. Climate, 26, 8495-8512, https://doi.org/10.1175/JCLI-D-13-00029.1.

— , and Coauthors, 2016: Confronting weather and climate models with observational data from soil moisture networks over the United States. J. Hydrometeor., 17, 1049-1067, https://doi.org/10.1175/JHM-D-15-0196.1.

—, S. Halder, and R. Bombardi, 2018: On the harvest of predictability from land states in a global forecast model. J. Geophys. Res. Atmos., 123, 13111-113 127, https://doi.org/10.1029/2018JD029103.

Duan, Y., and S. Kumar, 2020: Predictability of seasonal streamflow and soil moisture in National Water Model and in a humid AlabamaCoosa-Tallapoosa River basin. J. Hydrometeor., https://doi.org/ 10.1175/JHM-D-19-0206.1, in press.

Entekhabi, D., and Coauthors, 2014: SMAP Handbook-Soil Moisture Active Passive: Mapping Soil Moisture and Freezel Thaw from Space. Jet Propulsion Laboratory, $180 \mathrm{pp}$.

Entin, J. K., A. Robock, K. Y. Vinnikov, S. E. Hollinger, S. Liu, and A. Namkhai, 2000: Temporal and spatial scales of observed soil moisture variations in the extratropics. J. Geophys. Res., 105, 11 865-11 877, https://doi.org/10.1029/2000JD900051.

Evans, J. P., X. H. Meng, and M. F. McCabe, 2017: Land surface albedo and vegetation feedbacks enhanced the millennium drought in south-east Australia. Hydrol. Earth Syst. Sci., 21, 409-422, https://doi.org/10.5194/hess-21-409-2017.

Eyring, V., S. Bony, G. A. Meehl, C. A. Senior, B. Stevens, R. J. Stouffer, and K. E. Taylor, 2016: Overview of the Coupled Model Intercomparison Project Phase 6 (CMIP6) experimental design and organization. Geosci. Model Dev., 9, 19371958, https://doi.org/10.5194/gmd-9-1937-2016.

Ferguson, C. R., E. F. Wood, and R. K. Vinukollu, 2012: A global intercomparison of modeled and observed land-atmosphere coupling. J. Hydrometeor., 13, 749-784, https://doi.org/10.1175/ JHM-D-11-0119.1.

Findell, K. L., and E. A. B. Eltahir, 2003: Atmospheric controls on soil moisture-boundary layer interactions. Part I: Framework development. J. Hydrometeor., 4, 552-569, https://doi.org/ 10.1175/1525-7541(2003)004<0552:ACOSML>2.0.CO;2.
Guo, Z., and P. A. Dirmeyer, 2006: Evaluation of the Second Global Soil Wetness Project soil moisture simulations: 1. Intermodel comparison. J. Geophys. Res., 111, D22S02, https:// doi.org/10.1029/2006JD007233.

, and _ 2013: Interannual variability of land-atmosphere coupling strength. J. Hydrometeor., 14, 1636-1646, https:// doi.org/10.1175/JHM-D-12-0171.1.

— , and Coauthors, 2006: GLACE: The Global Land-Atmosphere Coupling Experiment. Part II: Analysis. J. Hydrometeor., 7, 611-625, https://doi.org/10.1175/JHM511.1.

_ P. A. Dirmeyer, and T. DelSole, 2011: Land surface impacts on subseasonal and seasonal predictability. Geophys. Res. Lett., 38, L24812, https://doi.org/10.1029/2011GL049945.

,,,--- and R. D. Koster, 2012: Rebound in atmospheric predictability and the role of the land surface. J. Climate, $\mathbf{2 5}$, 4744-4749, https://doi.org/10.1175/JCLI-D-11-00651.1.

Held, I. M., and B. J. Soden, 2006: Robust responses of the hydrological cycle to global warming. J. Climate, 19, 5686-5699, https://doi.org/10.1175/JCLI3990.1.

, T. L. Delworth, J. Lu, K. L. Findell, and T. R. Knutson, 2005: Simulation of Sahel drought in the 20th and 21st centuries. Proc. Natl. Acad. Sci. USA, 102, 17 891-17 896, https://doi.org/ 10.1073/pnas.0509057102.

Hoell, A., M. Hoerling, J. Eischeid, K. Wolter, R. Dole, J. Perlwitz, T. Xu, and L. Cheng, 2016: Does El Niño intensity matter for California precipitation? Geophys. Res. Lett., 43, 819-825, https://doi.org/10.1002/2015GL067102.

Hoerling, M., J. Eischeid, A. Kumar, R. Leung, A. Mariotti, K. Mo, S. Schubert, and R. Seager, 2014: Causes and predictability of the 2012 Great Plains drought. Bull. Amer. Meteor. Soc., 95, 269-282, https://doi.org/10.1175/BAMS-D-13-00055.1.

Holgate, C. M., A. I. J. M. Van Dijk, J. P. Evans, and A. J. Pitman, 2019: The importance of the one-dimensional assumption in soil moisture-rainfall depth correlation at varying spatial scales. J. Geophys. Res. Atmos., 124, 2964-2975, https:// doi.org/10.1029/2018JD029762.

Hsu, H., M. H. Lo, B. P. Guillod, D. G. Miralles, and S. Kumar, 2017: Relation between precipitation location and antecedent/subsequent soil moisture spatial patterns. J. Geophys. Res. Atmos., 122, 63196328, https://doi.org/10.1002/2016JD026042.

Hurrell, J. W., J. J. Hack, D. Shea, J. M. Caron, and J. Rosinski, 2008: A new sea surface temperature and sea ice boundary dataset for the Community Atmosphere Model. J. Climate, 21, 5145-5153, https://doi.org/10.1175/2008JCLI2292.1.

, and Coauthors, 2013: The Community Earth System Model: A framework for collaborative research. Bull. Amer. Meteor. Soc., 94, 1339-1360, https://doi.org/10.1175/BAMS-D-12-00121.1.

Infanti, J. M., and B. P. Kirtman, 2016: Prediction and predictability of land and atmosphere initialized CCSM4 climate forecasts over North America. J. Geophys. Res. Atmos., 121, 12 690-12 701, https://doi.org/10.1002/2016JD024932.

Kam, J., J. Sheffield, and E. F. Wood, 2014: Changes in drought risk over the contiguous United States (1901-2012): The influence of the Pacific and Atlantic Oceans. Geophys. Res. Lett., 41, 5897-5903, https://doi.org/10.1002/2014GL060973.

Kay, J. E., and Coauthors, 2015: The Community Earth System Model (CESM) Large Ensemble Project: A community resource for studying climate change in the presence of internal climate variability. Bull. Amer. Meteor. Soc., 96, 1333-1349, https://doi.org/10.1175/BAMS-D-13-00255.1.

Kirtman, B. P., and Coauthors, 2014: The North American Multimodel Ensemble: Phase-1 seasonal-to-interannual prediction; phase-2 toward developing intraseasonal prediction. 
Bull. Amer. Meteor. Soc., 95, 585-601, https://doi.org/10.1175/ BAMS-D-12-00050.1.

Koster, R. D., and M. J. Suarez, 2001: Soil moisture memory in climate models. J. Hydrometeor., 2, 558-570, https://doi.org/ 10.1175/1525-7541(2001)002<0558:SMMICM > 2.0.CO;2.

_ , and G. K. Walker, 2015: Interactive vegetation phenology, soil moisture, and monthly temperature forecasts. J. Hydrometeor., 16, 1456-1465, https://doi.org/10.1175/JHM-D-14-0205.1.

_- and Coauthors, 2004: Regions of strong coupling between soil moisture and precipitation. Science, 305, 1138-1140, https:// doi.org/10.1126/science.1100217.

—, and Coauthors, 2006: GLACE: The Global Land-Atmosphere Coupling Experiment. Part I: Overview. J. Hydrometeor., 7, 590-610, https://doi.org/10.1175/JHM510.1.

zation to subseasonal forecast skill: First results from a multimodel experiment. Geophys. Res. Lett., 37, L02402, https:// doi.org/10.1029/2009GL041677.

_ - Y. H. Chang, H. L. Wang, and S. D. Schubert, 2016: Impacts of local soil moisture anomalies on the atmospheric circulation and on remote surface meteorological fields during boreal summer: A comprehensive analysis over North America. J. Climate, 29, 7345-7364, https://doi.org/10.1175/JCLI-D-16-0192.1.

Kumar, S., V. Merwade, W. Lee, L. Zhao, and C. Song, 2010: Hydroclimatological impact of century-long drainage in midwestern United States: CCSM sensitivity experiments. J. Geophys. Res., 115, D14105, https://doi.org/10.1029/2009JD013228.

, P. A. Dirmeyer, V. Merwade, T. DelSole, J. M. Adams, and D. Niyogi, 2013: Land use/cover change impacts in CMIP5 climate simulations: A new methodology and 21st century challenges. J. Geophys. Res. Atmos., 118, 6337-6353, https:// doi.org/10.1002/jgrd.50463.

_ D. Lawrence, P. Dirmeyer, and J. Sheffield, 2014a: Less reliable water availability in the 21 st century climate projections. Earth's Future, 2, 152-160, https://doi.org/10.1002/2013EF000159.

— , and Coauthors, 2014b: Effects of realistic land surface initializations on subseasonal to seasonal soil moisture and temperature predictability in North America and in changing climate simulated by CCSM4. J. Geophys. Res. Atmos., 119, 13 250-13 270, https://doi.org/10.1002/2014JD022110.

_ R. P. Allan, F. Zwiers, D. M. Lawrence, and P. A. Dirmeyer, 2015: Revisiting trends in wetness and dryness in the presence of internal climate variability and water limitations over land. Geophys. Res. Lett., 42, 10 867-10 875, https://doi.org/10.1002/2015GL066858.

—, F. Zwiers, P. A. Dirmeyer, D. M. Lawrence, R. Shrestha, and A. T. Werner, 2016: Terrestrial contribution to the heterogeneity in hydrological changes under global warming. Water Resour. Res., 52, 3127-3142, https://doi.org/10.1002/2016WR018607.

—-, M. Newman, Y. Wang, and B. Livneh, 2019: Potential reemergence of seasonal soil moisture anomalies in North America. J. Climate, 32, 2707-2734, https://doi.org/10.1175/ JCLI-D-18-0540.1.

Lawrence, D. M., and Coauthors, 2019: The Community Land Model version 5: Description of new features, benchmarking, and impact of forcing uncertainty. J. Adv. Model. Earth Syst., 11, 4245-4287, https://doi.org/10.1029/2018MS001583.

Liu, S., and Coauthors, 2017: Grand challenges in understanding the interplay of climate and land changes. Earth Interact., 21, https://doi.org/10.1175/EI-D-16-0012.1.

Liu, Y., G. Wu, and R. Ren, 2004: Relationship between the subtropical anticyclone and diabatic heating. J. Climate, 17, 682-698, https://doi.org/10.1175/1520-0442(2004)017<0682: RBTSAA $>2.0 . \mathrm{CO} ; 2$.
Livneh, B., and M. P. Hoerling, 2016: The physics of drought in the U.S. Central Great Plains. J. Climate, 29, 6783-6804, https:// doi.org/10.1175/JCLI-D-15-0697.1.

Luo, L. F., D. Apps, S. Arcand, H. T. Xu, M. Pan, and M. Hoerling, 2017: Contribution of temperature and precipitation anomalies to the California drought during 2012-2015. Geophys. Res. Lett., 44, 3184-3192, https://doi.org/10.1002/2016GL072027.

Mei, R., and G. Wang, 2012: Summer land-atmosphere coupling strength in the United States: Comparison among observations, reanalysis data, and numerical models. J. Hydrometeor., 13, 1010-1022, https://doi.org/10.1175/JHM-D-11-075.1.

Meng, X. H., J. P. Evans, and M. F. McCabe, 2014: The impact of observed vegetation changes on land-atmosphere feedbacks during drought. J. Hydrometeor., 15, 759-776, https://doi.org/ 10.1175/JHM-D-13-0130.1.

Miyasaka, T., and H. Nakamura, 2005: Structure and formation mechanisms of the Northern Hemisphere summertime subtropical highs. J. Climate, 18, 5046-5065, https://doi.org/ 10.1175/JCLI3599.1.

Murphy, A. H., and E. S. Epstein, 1989: Skill scores and correlation coefficients in model verification. Mon. Wea. Rev., 117, 572-582, https:// doi.org/10.1175/1520-0493(1989)117<0572:SSACCI >2.0.CO;2.

NCEI, 2019: U.S. billion-dollar weather and climate disasters. Accessed 9 December 2019, https://www.ncdc.noaa.gov/billions/.

Neale, R. B., and Coauthors, 2010: Description of the NCAR Community Atmosphere Model (CAM5.0). NCAR Tech. Note NCAR/TN-486+STR, 268 pp., www.cesm.ucar.edu/ models/cesm1.1/cam/docs/description/cam5_desc.pdf.

Newman, M., G. N. Kiladis, K. M. Weickmann, F. M. Ralph, and P. D. Sardeshmukh, 2012: Relative contributions of synoptic and low-frequency eddies to time-mean atmospheric moisture transport, including the role of atmospheric rivers. J. Climate, 25, 7341-7361, https://doi.org/10.1175/JCLI-D-11-00665.1.

Nicolai-Shaw, N., L. Gudmundsson, M. Hirschi, and S. I. Seneviratne, 2016: Long-term predictability of soil moisture dynamics at the global scale: Persistence versus large-scale drivers. Geophys. Res. Lett., 43, 8554-8562, https://doi.org/10.1002/2016GL069847.

Niu, G. Y., Z. L. Yang, R. E. Dickinson, and L. E. Gulden, 2005: A simple TOPMODEL-based runoff parameterization (SIMTOP) for use in global climate models. J. Geophys. Res., 110, D21106, https://doi.org/10.1029/2005JD006111.

Oleson, K. W., and Coauthors, 2013: Technical description of version 4.5 of the Community Land Model (CLM). NCAR Tech. Note NCAR/TN-503+STR, 420 pp., https://doi.org/ 10.5065/D6RR1W7M.

Orth, R., and S. I. Seneviratne, 2012: Analysis of soil moisture memory from observations in Europe. J. Geophys. Res., 117, D15115, https://doi.org/10.1029/2011JD017366.

_ and _ 2013: Predictability of soil moisture and streamflow on subseasonal timescales: A case study. J. Geophys. Res. Atmos., 118, 10 963-10 979, https://doi.org/10.1002/jgrd.50846. _, and - 2017: Variability of soil moisture and sea surface temperatures similarly important for warm-season land climate in the Community Earth System Model. J. Climate, 30, 2141-2162, https://doi.org/10.1175/JCLI-D-15-0567.1.

PaiMazumder, D., and J. M. Done, 2016: Potential predictability sources of the 2012 U.S. drought in observations and a regional model ensemble. J. Geophys. Res. Atmos., 121, 12 581-12 592, https://doi.org/10.1002/2016JD025322.

Pitman, A. J., and Coauthors, 2009: Uncertainties in climate responses to past land cover change: First results from the LUCID intercomparison study. Geophys. Res. Lett., 36 , L14814, https://doi.org/10.1029/2009GL039076. 
Quiring, S. M., T. W. Ford, J. K. Wang, A. Khong, E. Harris, T. Lindgren, D. W. Goldberg, and Z. Li, 2016: The North American Soil Moisture Database: Development and applications. Bull. Amer. Meteor. Soc., 97, 1441-1459, https:// doi.org/10.1175/BAMS-D-13-00263.1.

Rippey, B. R., 2015: The U.S. drought of 2012. Wea. Climate Extremes, 10, 57-64, https://doi.org/10.1016/j.wace.2015.10.004.

Roundy, J. K., C. R. Ferguson, and E. F. Wood, 2014: Impact of landatmospheric coupling in CFSv2 on drought prediction. Climate Dyn., 43, 421-434, https://doi.org/10.1007/s00382-013-1982-7.

Saha, S., and Coauthors, 2010: The NCEP Climate Forecast System Reanalysis. Bull. Amer. Meteor. Soc., 91, 1015-1058, https:// doi.org/10.1175/2010BAMS3001.1.

Santanello, J. A., Jr., J. Roundy, and P. A. Dirmeyer, 2015: Quantifying the land-atmosphere coupling behavior in modern reanalysis products over the U.S. Southern Great Plains. J. Climate, 28, 58135829, https://doi.org/10.1175/JCLI-D-14-00680.1.

— , and Coauthors, 2018: Land-atmosphere interactions: The LoCo perspective. Bull. Amer. Meteor. Soc., 99, 1253-1272, https://doi.org/10.1175/BAMS-D-17-0001.1.

Sardeshmukh, P. D., G. P. Compo, and C. Penland, 2000: Changes of probability associated with El Niño. J. Climate, 13, 4268-4286, https:// doi.org/10.1175/1520-0442(2000)013<4268:COPAWE >2.0.CO;2.

Schubert, S. D., M. J. Suarez, P. J. Pegion, R. D. Koster, and J. T. Bacmeister, 2008: Potential predictability of long-term drought and pluvial conditions in the U.S. Great Plains. J. Climate, 21, 802-816, https://doi.org/10.1175/2007JCLI1741.1.

— , and Coauthors, 2016: Global meteorological drought: A synthesis of current understanding with a focus on SST drivers of precipitation deficits. J. Climate, 29, 3989-4019, https:// doi.org/10.1175/JCLI-D-15-0452.1.

Seager, R., and M. Hoerling, 2014: Atmosphere and ocean origins of North American droughts. J. Climate, 27, 4581-4606, https://doi.org/10.1175/JCLI-D-13-00329.1.

_ R. Murtugudde, N. Naik, A. Clement, N. Gordon, and J. Miller, 2003: Air-sea interaction and the seasonal cycle of the subtropical anticyclones. J. Climate, 16, 1948-1966, https://doi.org/10.1175/ 1520-0442(2003)016<1948:AIATSC > 2.0.CO;2.

—, M. Hoerling, S. Schubert, H. Wang, B. Lyon, A. Kumar, J. Nakamura, and N. Henderson, 2015: Causes of the 2011-14 California drought. J. Climate, 28, 6997-7024, https:/doi.org/10.1175/ JCLI-D-14-00860.1.

Seneviratne, S. I., and Coauthors, 2013: Impact of soil moistureclimate feedbacks on CMIP5 projections: First results from the GLACE-CMIP5 experiment. Geophys. Res. Lett., 40, 5212-5217, https://doi.org/10.1002/grl.50956.

Sheffield, J., and E. F. Wood, 2011: Drought: Past Problems and Future Scenarios. Earthscan, 210 pp.

— , and Coauthors, 2013: North American climate in CMIP5 experiments. Part I: Evaluation of historical simulations of continental and regional climatology. J. Climate, 26, 92099245, https://doi.org/10.1175/JCLI-D-12-00592.1.

Swain, D. L., 2015: A tale of two California droughts: Lessons amidst record warmth and dryness in a region of complex physical and human geography. Geophys. Res. Lett., 42, 999910003 , https://doi.org/10.1002/2015GL066628.

Tang, Q. H., and G. Y. Leng, 2013: Changes in cloud cover, precipitation, and summer temperature in North America from 1982 to 2009. J. Climate, 26, 1733-1744, https://doi.org/10.1175/JCLI-D-12-00225.1.

Tawfik, A. B., and P. A. Dirmeyer, 2014: A process-based framework for quantifying the atmospheric preconditioning of surface-triggered convection. Geophys. Res. Lett., 41, 173-178, https://doi.org/10.1002/2013GL057984.
Taylor, C. M., C. E. Birch, D. J. Parker, N. Dixon, F. Guichard, G. Nikulin, and G. M. Lister, 2013: Modeling soil moistureprecipitation feedback in the Sahel: Importance of spatial scale versus convective parameterization. Geophys. Res. Lett., 40, 6213-6218, https://doi.org/10.1002/2013GL058511.

Taylor, K. E., R. J. Stouffer, and G. A. Meehl, 2012: An overview of CMIP5 and the experiment design. Bull. Amer. Meteor. Soc., 93, 485-498, https://doi.org/10.1175/BAMS-D-11-00094.1.

Teng, H., G. Branstator, A. B. Tawfik, and P. Callaghan, 2019: Circumglobal response to prescribed soil moisture over North America. J. Climate, 32, 4525-4545, https://doi.org/10.1175/JCLI-D-18-0823.1.

Teuling, A. J., and P. A. Troch, 2005: Improved understanding of soil moisture variability dynamics. Geophys. Res. Lett., 32, L05404, https://doi.org/10.1029/2004GL021935.

Thornton, P. E., and N. A. Rosenbloom, 2005: Ecosystem model spin-up: Estimating steady state conditions in a coupled terrestrial carbon and nitrogen cycle model. Ecol. Modell., 189, 25-48, https://doi.org/10.1016/j.ecolmodel.2005.04.008.

_- and Coauthors, 2002: Modeling and measuring the effects of disturbance history and climate on carbon and water budgets in evergreen needleleaf forests. Agric. For. Meteor., 113, 185222, https://doi.org/10.1016/S0168-1923(02)00108-9.

van den Hurk, B., and Coauthors, 2016: LS3MIP (v1.0) contribution to CMIP6: The Land Surface, Snow and Soil Moisture Model Intercomparison Project—Aims, setup and expected outcome. Geosci. Model Dev., 9, 2809-2832, https://doi.org/10.5194/gmd-9-2809-2016.

Vinnikov, K. Y., A. Robock, N. A. Speranskaya, and A. Schlosser, 1996: Scales of temporal and spatial variability of midlatitude soil moisture. J. Geophys. Res., 101, 7163-7174, https://doi.org/ 10.1029/95JD02753.

Wang, S. Y., L. Hipps, R. R. Gillies, and J. H. Yoon, 2014: Probable causes of the abnormal ridge accompanying the 2013-2014 California drought: ENSO precursor and anthropogenic warming footprint. Geophys. Res. Lett., 41, 3220-3226, https://doi.org/ 10.1002/2014GL059748.

Wei, J. F., Q. J. Jin, Z. L. Yang, and P. A. Dirmeyer, 2016: Role of ocean evaporation in California droughts and floods. Geophys. Res. Lett., 43, 6554-6562, https://doi.org/10.1002/2016GL069386.

Wey, H. W., M. H. Lo, S. Y. Lee, J. Y. Yu, and H. H. Hsu, 2015: Potential impacts of wintertime soil moisture anomalies from agricultural irrigation at low latitudes on regional and global climates. Geophys. Res. Lett., 42, 8605-8614, https://doi.org/ 10.1002/2015GL065883.

Williams, A. P., R. Seager, J. T. Abatzoglou, B. I. Cook, J. E. Smerdon, and E. R. Cook, 2015: Contribution of anthropogenic warming to California drought during 2012-2014. Geophys. Res. Lett., 42, 6819-6828, https://doi.org/10.1002/2015GL064924.

Wu, G., and Y. Liu, 2003: Summertime quadruplet heating pattern in the subtropics and the associated atmospheric circulation. Geophys. Res. Lett., 30, 1201, https://doi.org/10.1029/2002GL016209.

Wu, W., and R. E. Dickinson, 2004: Time scales of layered soil moisture memory in the context of land-atmosphere interaction. J. Climate, 17, 2752-2764, https://doi.org/10.1175/15200442(2004)017<2752:TSOLSM >2.0.CO;2.

— M. A. Geller, and R. E. Dickinson, 2002: The response of soil moisture to long-term variability of precipitation. J. Hydrometeor., $\mathbf{3}$, 604-613, https://doi.org/10.1175/1525-7541(2002)003<0604: TROSMT $>2.0 . \mathrm{CO} ; 2$.

Yeager, S., and Coauthors, 2018: Predicting near-term changes in the Earth system: A large ensemble of initialized decadal prediction simulations using the Community Earth System Model. Bull. Amer. Meteor. Soc., 99, 1867-1886, https:// doi.org/10.1175/BAMS-D-17-0098.1. 